\title{
Distribución del ingreso, rotación del capital y niveles de rentabilidad*
}

\section{Distribution of Income, Capital Turnover and Profitability Levels}

Esteban Ezequiel Maito**

\section{RESUMEN}

Se realiza un análisis del proceso de valorización en Chile, Japón, Países Bajos y eu, realizando estimaciones del capital constante y variable adelantado, la composición y rotación del capital, y la tasa de ganancia sobre capital adelantado. Además, se analiza especialmente el papel jugado por la rotación del capital en el proceso de valorización. La rotación del capital tiende a ser superior en los países centrales, en virtud del mayor desarrollo de la fuerza productiva. De este modo, en los Países Bajos, EU y Japón existe una mayor participación asalariada en el ingreso, representando, a su vez, los salarios ajustados por la rotación del capital, una proporción menor en relación al capital total adelantado y al ingreso, en comparación con países periféricos como Chile.

Palabras clave: tasa de ganancia, distribución del ingreso, rotación del capital, composición del capital, tasa de plusvalía.

Clasificación JEL: O57, P16.

\begin{abstract}
This paper analyzes the valorization process in Chile, Japan, Netherlands and United States, making estimates for advanced constant and variable capital, turnover speed, capital composition and profit rate on total advanced capital. Furthermore, it analyzes the turnover speed role in the valorization process. In core countries, turnover speed of capital tends to be higher due to a larger development of productive forces. Thus, in Netherlands, United States and Japan there is higher wage participation on income, representing at the same time the wage bill adjusted by capital turnover, a lower proportion related to total capital and income, compared to peripheral countries like Chile.
\end{abstract}

Keywords: profit rate, income distribution, turnover speed, capital composition, surplus value rate.

JEL classification: O57, P16.

* Fecha de recepción: 20/11/2013. Fecha de aprobación: 13/04/2016.

** Universidad de Buenos Aires. Correo electrónico: eemaito@gmail.com. 


\section{INTRODUCCIÓN}

El presente artículo tiene como objetivo principal realizar una estimación de la velocidad de rotación del capital circulante constante y variable en la producción, en términos marxianos, a partir de cuatro casos nacionales para los que se pudo reunir la información necesaria (Chile, Estados Unidos, Japón y Países Bajos), y adicionalmente aportar elementos para el análisis de la influencia de la rotación del capital en los niveles de rentabilidad y en la distribución del ingreso en tanto expresión de procesos de producción capitalistas.

Los escasos antecedentes a este respecto tienen que ver, entre otras cosas, con las dificultades para reunir los datos estadísticos que permitan un cálculo aproximado de la rotación, además del papel marginal que tienen la rentabilidad $\mathrm{y}$, en menor medida, la distribución del ingreso para las corrientes económicas hegemónicas. Existen, no obstante, numerosos trabajos, tanto sobre el análisis de los niveles de rentabilidad como sobre la distribución del ingreso. ${ }^{1}$ Sin embargo, son contados los casos en los cuales se introduce la rotación del capital en los cálculos, siendo este el primer estudio comparativo al respecto. ${ }^{2}$

Estimada la velocidad de rotación del capital circulante, se tiene, entonces, una noción más aproximada de la tasa de ganancia concreta de la economía en relación a estimaciones que, si bien son de utilidad para comprender la evolución de la rentabilidad, al considerar las ganancias sobre el capital fijo o, en su defecto, sobre el capital total, suponiendo constante la rotación, tienden a sobreestimar o subestimar sus niveles concretos. Éstos son subestimados hasta por los propios capitalistas cuando calculan sus márgenes anuales de ganancia, dado que computan el capital circulante en insumos y salarios sin ajuste alguno por las rotaciones realizadas, tal como señalara el mismo Engels en El capital. ${ }^{3}$ Del

\footnotetext{
${ }^{1}$ Algunos análisis sobre la rentabilidad en distintos países pueden consultarse en Reati (1986), Reati y Roberts (1989), Mariña y Moseley (2001), Duménil y Levy (2002; 2005), Iñigo (2007), Marquetti, Maldonado y Lautert (2010) y Maito (2012; 2014; 2015), entre otros. Para análisis comparativos de distribución, véase Lindenboim, Kennedy y Graña (2011), y Guerriero (2012).

${ }^{2}$ Alemi y Foley (1997), Fichtenbaum (1988) y Jones (2012), en el caso de EU, y Maito (2012), en el de Chile.

${ }^{3}$ En el tomo III de El capital, la relación entre rotación y tasa de ganancia -si bien se encuentra implícita en todos los escritos de Marx- es introducida por el propio Engels en un capítulo especial (cap. IV, "Cómo influye la rotación sobre la cuota de ganancia") del mencionado tomo (Marx, 2012, pp. 84-90). A este respecto, allí se afirma: "Pero en la mayoría de los casos, ni el propio capitalista sabe a cuánto asciende en un negocio el capital variable [...]; aunque llevase una cuenta especial sobre los salarios abonados, esta cuenta registraría al final del año la suma pagada por este concep-
} 
mismo modo, a lo largo del trabajo se irá observando la incidencia que tiene la rotación en otras categorías, como la tasa de plusvalía o la composición de valor del capital.

El trabajo se estructura de la siguiente manera. En una primera sección, se introducen algunos aspectos teóricos fundamentales. En la segunda, se abordan los niveles de rentabilidad concretos de los cuatro países en cuestión. Luego, se presentan las estimaciones realizadas de la velocidad de rotación del capital circulante. La cuarta parte toca la tasa simple y la tasa anual de plusvalía para cada país a partir de la incidencia particular de la velocidad de rotación. En la quinta, se analiza la distribución del ingreso convencionalmente entendida como expresión del proceso de producción capitalista y las sucesivas rotaciones anuales que realiza el propio capital variable. En una sexta sección, se aborda la incidencia de la velocidad de rotación del capital circulante en los niveles alcanzados por la composición orgánica del capital, tras lo cual se exponen las conclusiones.

\section{EL PROCESO DE PRODUCCIÓN CAPITALISTA Y LA ROTACIÓN DEL CAPITAL}

El proceso de producción capitalista es un proceso de valorización $\left(D-D^{\prime}\right)$ por medio de la explotación de la fuerza de trabajo $\left(D-M \ldots P \ldots-M^{\prime}-D^{\prime}\right)$. El capital adelantado en forma de dinero $(D)$ es intercambiado por mercancías $(M)$-medios de producción, insumos (capital constante, CC) y fuerza de trabajo (capital variable, $C V$ )-. Dado que el capital que toma la forma de medios de producción e insumos en general es conservado y transferido al producto final en el proceso de trabajo, es un capital constante. Su magnitud de valor no varía en el proceso productivo. En cambio, el capital con el que se adquiere fuerza de trabajo es un capital variable, en tanto que aquella reproduce su valor laborando cierto número de horas y produce un valor adicional al de su reproducción.

La fuerza de trabajo, a diferencia de los medios de producción y los insumos, tiene la propiedad -el valor de uso- de generar un valor adicional al de su reproducción. Dado que el valor de la fuerza de trabajo está representado por determinada cantidad de medios de vida que encarnan, en tanto valores de uso, determinada cantidad de tiempo de trabajo socialmente necesario, este tiempo, expresado en términos de horas por día, tiene una magnitud específica que sólo

to, es decir la suma $v n$, pero no el mismo capital variable $v[N$. del A.: $n$ es igual al número de rotaciones anuales]" (Marx, 2012, p. 88). 
debe ocupar una parte de la jornada laboral. ${ }^{4}$ Si no fuera así, el capitalista, habiendo adelantado cierto capital en medios de producción y en fuerza de trabajo, se encontraría, finalizado el proceso, con un producto de idéntico valor al capital inicial y no se habría producido valorización alguna.

De este modo, se realiza el proceso de producción propiamente dicho $(\ldots P \ldots)$ en el que la fuerza de trabajo, empleando los medios de producción, transforma los insumos en una masa de mercancías de un valor global mayor al previo $\left(M^{\prime}\right)$. Así, en el producto final, aparece transferido el capital constante empleado (en insumos y en parte del valor de los medios de producción) y un valor adicional -que se descompone en capital variable (valor de reproducción de la fuerza de trabajo retribuida luego por el capitalista) y plusvalor (valor generado por la fuerza de trabajo que excede el de su reproducción y que al capitalista no le cuesta nada) - agregado e incorporado a la masa de mercancías producidas. Este valor incrementado y materializado en la masa final de mercancías $\left(M^{\prime}\right)$ es luego intercambiado por un equivalente dinerario $\left(D^{\prime}\right)$, completándose así el circuito del capital.

Las materias primas y auxiliares pierden su forma en el proceso productivo y transfieren la totalidad de su valor al producto final. En tanto valores de uso, ingresan a la circulación junto con su valor. Los medios de producción (infraestructura, maquinaria, etcétera) conservan su forma en cada proceso productivo del que participan. Transfieren su valor a lo largo de varios procesos productivos y años. Su consumo implica cierto desgaste, que no es más que la pérdida paulatina de su valor de uso y, en consecuencia, de su valor, que es transferido del mismo modo al producto. ${ }^{5}$ Sin embargo, a diferencia de las materias

\footnotetext{
4 "Pero el trabajo pretérito encerrado en la fuerza de trabajo y el trabajo vivo que ésta puede desarrollar, su costo diario de conservación y su rendimiento diario, son dos magnitudes completamente distintas. La primera determina su valor de cambio, la segunda forma su valor de uso. El que para alimentar y mantener en pie la fuerza de trabajo durante veinticuatro horas haga falta media jornada de trabajo, no quiere decir, ni mucho menos, que el obrero no pueda trabajar durante una jornada entera. El valor de la fuerza de trabajo y su valorización en el proceso de trabajo son, por tanto, dos factores completamente distintos. Al comprar la fuerza de trabajo, el capitalista no perdía de vista esta diferencia de valor. El carácter útil de la fuerza de trabajo, en cuanto apto para fabricar hilado o botas, es conditio sine qua non, toda vez que el trabajo, para poder crear valor, ha de invertirse siempre en forma útil. Pero el factor decisivo es el valor de uso especifico de esta mercancía, que le permite ser fuente de valor, y de más valor que el que ella misma tiene" (Marx, 1968a, p.144).

${ }^{5}$ En términos convencionales del cálculo del stock y el consumo de capital fijo, existen distintas posturas respecto a la función de depreciación del capital fijo, es decir, a la forma en que se produce su desgaste a lo largo de su vida útil. Por ejemplo, la función lineal - la más aceptada en la
} 
primas, sólo circula en cuanto valor. En cuanto valor de uso no ingresa a la circulación, "no es enajenado por su poseedor; se mantiene en sus manos. Circula sólo en su aspecto formal como capital, como valor perenne [...], sólo se realiza como valor mientras permanece como valor de uso en las manos del capitalista" (Marx, 2007, pp. 202-203).

El capital constante invertido en medios de producción, como edificaciones, infraestructura y maquinaria, transfiere una parte ínfima de su valor en cada proceso productivo. Este capital es un capital fijo en el sentido de que completa su circuito y es recuperado en un largo plazo, encontrándose justamente fijado en su forma de capital productivo o capital industrial. Su rotación involucra un periodo de varios años, en el que su valor circula y completa así su ciclo.

En cambio, el capital destinado a la compra de fuerza de trabajo (capital variable), así como el capital invertido en materias primas y auxiliares (capital constante circulante), es transferido a lo largo del proceso productivo y reaparece completamente en el producto final. El capital circulante, entonces, cambia íntegramente su forma de capital productivo a capital-mercancías como resultado del propio proceso de producción.

Marx afirma que, en su conjunto, la circulación se presenta en una triple faceta: 1) como proceso total, $D-M \ldots P \ldots M^{\prime}-D^{\prime}$; 2) a manera de gran circulación, como "el movimiento del capital fuera de la fase de producción, en la cual su tiempo aparece, en contraposición al tiempo de trabajo (...P...), como tiempo de circulación" y 3) como pequeña circulación entre el capital y la fuerza de trabajo, que, de acuerdo con Marx (2007, pp. 200-201), “acompaña al proceso de producción y aparece como contrato".

En tanto proceso total, no es más que el circuito completo realizado por el capital en sus distintas fases, con su correspondiente valorización; "es el periodo de tiempo que transcurre desde el momento en que se desembolsa el valorcapital, bajo una determinada forma, hasta el momento en que el valor-capital en acción retorna a su punto de partida, en la misma forma inicial" (Marx, 1968b, pp. 136). En la presente investigación, se estima justamente el tiempo total que el capital circulante, constante y variable, demanda para recorrer todas esas fases.

Gran circulación se considera la esfera en la que mercancías producidas y dinero son intercambiados, representando una fracción particular del circuito

actualidad- supone que el activo se desgasta exactamente en la misma proporción cada año. Marx (1968a, pp. 153-154) parece haber sostenido también este tipo de función de depreciación. Otras funciones suponen, en cambio, un mayor desgaste relativo en los años iniciales o en los años finales de la vida útil del activo. 
completo. Es, por tanto, en la primera $(D-M)$ y en la última fase $\left(M^{\prime}-D^{\prime}\right)$ que el capital permanece en la esfera de la circulación. ${ }^{6}$

Mientras circula, mientras se encuentra en las dos fases características de la esfera de circulación, no produce mercancías ni plusvalía. Sólo lo hace cuando se presenta como capital productivo (... P...). La tendencia del capital es, en este momento, también a reducir el tiempo de producción requerido para la producción de las mercancías. ${ }^{7}$ Pero en la circulación el capital no incrementa su valor. Por el contrario, el valor se encuentra a la espera de ser intercambiado por un equivalente, ya sea para iniciar la fase de producción (...P...) o para completar su ciclo de valorización como $D^{\prime}$ y ser reinvertido eventualmente en forma ampliada. El tiempo de circulación es, entonces, un momento necesario del proceso total de valorización del capital, pero que se contrapone al tiempo de

\footnotetext{
${ }^{6}$ Naturalmente, se habla de primera y última fase considerando un capital particular. La primera fase de un capital particular $(D-M)$ es simultáneamente la última fase de otro capital $\left(M^{\prime}-D^{\prime}\right)$, así como la última fase del primero $\left(M^{\prime}-D^{\prime}\right)$ es la primera fase de otro capital $(D-M)$ o, en su defecto, una transacción cuyo fin es el consumo personal del obrero o el capitalista. "Dentro de la esfera de circulación, el capital recorre en un sentido o en otro las dos fases contrapuestas $M-D$ y $D-M$. Su tiempo de circulación se divide, por tanto, en dos partes; el tiempo que necesita para convertirse de mercancía en dinero y el tiempo necesario para convertirse de dinero en mercancía. Sabemos ya por el análisis de la circulación simple de mercancías que la de la venta, representa la parte más difícil de su metamorfosis y, por tanto, en condiciones normales, la mayor parte del tiempo de circulación. Cuando reviste la forma de dinero, el valor puede invertirse en cualquier momento. En cambio, como mercancía, necesita convertirse previamente en dinero para ser directamente cambiable y estar en condiciones de actuar a cada instante. Sin embargo, el proceso circulatorio del capital en su fase $D-M$ supone precisamente su transformación en mercancías que representen determinados elementos del capital productivo en la base dada de inversión. Puede ocurrir que los medios de producción no se encuentren en el mercado, sino que deban ser producidos previamente, que haya que ir a buscarlos a mercados lejanos, que se presenten lagunas en su abastecimiento normal, cambios de precios, etcétera.; en una palabra, todo un cúmulo de circunstancias que no se traslucen en la simple fórmula $D-M$, pero que absorben unas veces más y otras menos tiempo, en esta parte de la fase de circulación. Las fases $M-D$ y $D-M$ se hallan separadas en el tiempo, pudiendo también ocurrir que lo estén en el espacio, que el mercado de compra y el de venta sean mercados geográficamente distintos" (Marx, 1968b, p. 112)

7 “Los factores que aumentan el producto de cada jornada, tales como la cooperación, la división de trabajo, el empleo de maquinaria, etcétera, acortan, al mismo tiempo, el periodo de trabajo en los actos coherentes de producción. Así, por ejemplo, el empleo de maquinaria acorta el plazo de construcción de casas, puentes, etcétera [...]. Sin embargo, estos perfeccionamientos que acortan el periodo de trabajo y, por tanto, con vista al cual se desembolsa el capital circulante, exigen casi siempre un mayor desembolso de capital fijo" (Marx, 1968b, p. 209). La reducción del tiempo de producción se encuentra relacionada con el incremento de la productividad del trabajo, tema que Marx desarrolló con mayor detalle en el tomo i de El capital (Marx, 1968a).
} 
producción en tanto y en cuanto es solamente en este último en el que se produce plusvalor. ${ }^{8}$

Por último, la pequeña circulación del capital variable se refiere al capital-dinero adelantado al obrero por su fuerza de trabajo ( $D-M$, que, siendo más concretos, es $D-F T$ ). Este capital-dinero no ingresa formalmente en la producción, sino que es retirado de la circulación ahora como dinero y salario del trabajador, finalmente cambiado por bienes de consumo. Sin embargo, su valor, junto con un plusvalor, aparece reproducido por la actividad de la fuerza de trabajo y recorre en definitiva el circuito completo. ${ }^{9}$

8 “El tiempo de circulación, pues, se presenta como tiempo en que está abolida la capacidad que tiene el capital de reproducirse y, por tanto, de reproducir la plusvalía. La productividad del capital -esto es, su creación de plusvalores- está, pues, en proporción inversa al tiempo de circulación y alcanzaría el máximo si el último descendiese a cero. La circulación, por ser el tránsito del capital a través de los diversos momentos, conceptualmente determinados, de su metamorfosis necesaria, de su proceso vital, constituye una condición ineludible para el capital, una condición puesta por su propia naturaleza [...]. El tiempo de circulación no es tiempo durante el cual el capital crea valor, sino tiempo en el que el capital realiza el valor creado en el proceso de producción; no aumenta la cantidad del capital, sino que lo pone en otra determinación formal que corresponde a éste [...] La tendencia necesaria del capital es pues circulación sin tiempo de circulación, y esta tendencia es la determinación fundamental del crédito y de los mecanismos crediticios del capital" (Marx, 2007, pp. 176-178). Con el descenso del tiempo de circulación, "cantidades sucesivas de mercancías pueden expedirse en periodos sucesivos de más corta duración y llegar así, sucesivamente, al mercado, sin acumularse en grandes masas como capital potencial en mercancías hasta su envío efectivo. Esto hace, además, por tanto, que el reflujo del capital se reparta entre periodos de tiempo sucesivos más cortos, haciendo que una parte se convierta constantemente en capital-dinero, mientras la parte restante circula como capital-mercancías. Mediante este reparto del reflujo del capital en varios periodos sucesivos, se acorta el tiempo total de circulación y también, como es lógico, el tiempo de rotación" (Marx, 1968b, pp. 222-223). Por otra parte, "el crédito, en la medida que se fomenta y acelera la concentración del capital en pocas manos, contribuye también a acortar el periodo de trabajo y, por tanto, el tiempo de rotación” (Marx, 1968b, pp. 209).

${ }^{9}$ En rigor, el capitalista no les adelanta a los obreros el capital variable, sino que son éstos quienes le adelantan al capitalista su fuerza de trabajo en primer lugar. De todas formas, esto no afecta el hecho de que el capitalista debe disponer de un monto de capital suficiente para el pago de salarios e insumos durante el periodo en que se realiza el circuito, recuperando su capital cuando este último periodo es más dilatado que la periodicidad con la que se abonan en definitiva los salarios: "Aunque la duración del proceso de trabajo diario es la misma en ambos casos, media una diferencia muy importante en cuanto a la duración del acto de producción, es decir, en cuanto a la duración de los repetidos procesos de trabajo que se requieren para elaborar el producto y lanzarlo como mercancía al mercado y, por tanto, para convertirlo de capital productivo en capital-mercancías [...] dentro de los plazos con vista a los cuales se desembolsa un capital dado, es evidente que la diferencia en cuanto a la duración del acto de producción tiene que traducirse necesariamente en una diferencia en cuanto al ritmo de la rotación. Supongamos que una fábrica de hilados y una fábrica de locomotoras funcionen a base de la misma inversión de capital [...]. Al final de la semana, al entregar la 
Es de recordar, que en el presente trabajo se considera la rotación del capital circulante y, por tanto, el tiempo en el que este realiza todo el circuito como proceso total que involucra conjuntamente tiempo de producción y tiempo de circulación. El capital va, de este modo, transmutándose de capital-dinero $(D)$ a capital-mercancías $(M)$, y luego a capital productivo $(P)$, para finalmente retornar a la forma de capital-mercancías $\left(M^{\prime}\right)$ y capital-dinero $\left(D^{\prime}\right)$ de un mayor valor. Este último paso es el que implica la venta en el mercado $\left(M^{\prime}-D^{\prime}\right)$, la realización de la ganancia y del ciclo de valorización.

En términos marxianos, la tasa de ganancia surge del cociente entre las ganancias y el capital adelantado en maquinaria e infraestructura (capital constante fijo, $C C F$ ), en insumos (capital constante circulante, CCC) y salarios (capital variable, $C V$ ). El capital circulante en insumos y salarios consumido a lo largo del año debe dividirse por el número de rotaciones anuales que realiza $(N)$.

El capitalista adelanta el capital circulante, los insumos y los salarios, pero los recupera no en el lapso de un año, sino cuando la mercancía que contiene dicho capital es vendida, completando su ciclo, de forma tal que si el capitalista compra una tonelada de acero en enero y en marzo se vende transformada en tubos, para abril ya ha recuperado el monto pagado por el acero en enero, por lo que para la producción de abril sólo deberá reinvertir el capital circulante adelantado en enero. El capital circulante aparece en el producto final luego de cada proceso productivo y es recuperado por el capitalista una vez que las mercancías son vendidas, para ser nuevamente lanzado a la producción y valorizado. Dado que la fuerza de trabajo, mediante la maquinaria, es la que transforma los insu-

cantidad elaborada de hilado, el fabricante de esta rama se reembolsa del capital circulante por él invertido (aquí, prescindimos de la plusvalía), reponiéndose asimismo del desgaste del capital fijo que encierra el valor de los hilados. Esto le permite, pues, acometer de nuevo el mismo ciclo con el mismo capital. Éste ha descrito su rotación. En cambio, el fabricante de locomotoras tendrá que invertir semana tras semana, durante tres meses más y más capital en salarios y materias primas, y sólo al cabo de los tres meses, una vez construida y entregada la locomotora, el capital circulante que durante todo este tiempo se ha ido invirtiendo poco a poco en un solo acto de producción, en la elaboración de una sola mercancía, reaparecerá bajo una forma que le permita iniciar de nuevo su ciclo" (Marx, 1968b, pp. 203-204). Por su parte, Reuten (2005) tiende a suponer que el caso general es aquel en el que la fuerza de trabajo es adelantada por los trabajadores al capitalista, sin que éste necesite de fondos adicionales. Por lo tanto, el tiempo de producción y circulación sería generalmente menor al periodo que media entre los pagos de salarios. Entendemos que, por el contrario, no tiende a ser el caso general. No obstante, de lo desarrollado en el presente trabajo llegamos a conclusiones similares que Reuten sobre la menor relevancia del capital variable dentro del capital adelantado (aspecto que expondremos en la última sección). 
mos que representan el capital constante circulante, la rotación del capital variable es similar a la de aquél. ${ }^{10}$

Por lo anteriormente desarrollado, la categorías "consumo intermedio" (CI) y "masa salarial" (MS) de las cuentas nacionales no pueden ser utilizadas como equivalentes del capital circulante constante y variable adelantados sin conocer la velocidad de rotación del capital, o sea:

$$
T G=\frac{G}{C C F+\frac{C I}{N}+\frac{M S}{N}}=\frac{G}{C C F+C C C+C V} .
$$

Si utilizáramos el consumo intermedio y la masa salarial como equivalentes, que en rigor representan el capital circulante constante y variable efectivamente consumidos, no adelantados, estaríamos realizando un cálculo que supondría que el capital circulante realiza sólo una rotación anual.

En los países en los que el capital no produce la generalidad de las mercancías y la producción de mercancías portadoras de renta del suelo (agrarias o mineras) es un eje central en la acumulación, la rotación del capital tenderá a ser menor que en aquéllos con la capacidad de producir la totalidad de las mercancías, dado que los propios tiempos de producción y circulación, expresión del mayor desarrollo relativo de la fuerza productiva, son menores. Particularmente, en los países agrarios, la producción primaria requiere un tiempo de producción que está fuertemente regulado por los ciclos naturales del crecimiento de los cultivos. En los países mineros, no parece existir esta limitación, pero probablemente existe una presión sobre la rotación dada por el agotamiento de las canteras y la mayor dificultad para la extracción, que en definitiva prolongue el tiempo de rotación, principalmente el tiempo de producción.

La mayor rotación del capital en los países centrales no se verá mermada por el mayor crecimiento relativo de los servicios en relación a la industria que se ha vivido en las últimas décadas. Por el contrario, al coincidir en los servicios

10 "El capital circulante variable invertido durante la producción sólo puede funcionar de nuevo en el proceso de circulación siempre y cuando que el producto en que su valor se reproduce se venda, se convierta de capital-mercancías en capital-dinero, para luego volver a invertirse en el pago de fuerza de trabajo. Y otro tanto acontece con el capital circulante constante invertido en la producción (en los materiales de producción) y cuyo valor reaparece como parte del valor en el producto" (Marx. 1968b, pp. 262). No obstante, puede ocurrir que el cambio de forma $D-M$ para el caso de los medios de producción se realice con cierta anterioridad en relación $D-M$ para el caso de la fuerza de trabajo, al menos cuando un capital inicia su actividad. 
la producción y el consumo mismo de la mercancía, la velocidad de rotación del capital circulante en estas actividades es probablemente mayor. Sin embargo, esto último no puede aplicarse del mismo modo a los servicios en los países periféricos, en los que dicho sector presenta una importante heterogeneidad y se encuentra, en última instancia, menos regido por relaciones capitalistas plenamente desarrolladas. En el presente trabajo, la rotación del capital ha sido estimada como el cociente entre los costos totales de la economía (consumo intermedio, masa salarial y consumo de capital fijo) y el stock total de inventarios, de acuerdo a Fichtenbaum (1988, p. 224).

Finalmente, cabe aclarar que no se considera la distinción entre trabajadores productivos e improductivos. A fines de realizar un análisis más "estructural", algunos autores consideran que los salarios de los trabajadores improductivos para el capital -los cuales son necesarios para la producción del capitalista, pero no generan plusvalía- se financian con la plusvalía. Es decir, ésta se transformaría en salarios improductivos y ganancia. La tasa de plusvalía en estos términos sería mayor, dado que el verdadero monto del capital variable sería exclusivamente el representado por los salarios de los trabajadores productivos y el plusvalor estaría representado tanto por las ganancias de los capitalistas como por los salarios de los trabajadores improductivos de las empresas de aquéllos. En este sentido, se considera más concretamente el comportamiento de la rentabilidad, siendo los salarios de los trabajadores improductivos un costo más para el capitalista, cuyo monto, por otra parte, no ingresa en el numerador de la tasa de plusvalía ni en la de ganancia y sí lo hace en el denominador.

\section{La tasa de ganancia en Chile, JaPón, Países Bajos y eU}

La tasa de ganancia presentó una tendencia descendente en Chile, Japón, Países Bajos y Estados Unidos (EU) hasta principios de la década de los ochenta, para luego mostrar una recuperación de variada intensidad, ${ }^{11}$ con excepción del caso japonés, en el que la tasa continuó exhibiendo un marcado descenso. Desde los cincuenta hasta inicios de los setenta, la tasa de ganancia había sido claramente superior en el país asiático, en el que la expansión de la producción fue obviamente mucho más importante.

\footnotetext{
${ }^{11}$ Los cálculos de las tasas de plusvalía y de ganancia chilenas en este trabajo no coinciden con los de Maito (2012), debido a que, para armonizar la comparación con los datos de ganancias de Japón y los Países Bajos, no se ha desagregado el ingreso mixto (cuentapropistas) de las ganancias.
} 
Sin embargo, con posterioridad a la crisis general de rentabilidad de los setenta e inicios de los ochenta, la tasa en Japón no experimentó el ascenso parcial que comúnmente suele presentarse en la generalidad de los países, incluidos los tres restantes del presente estudio. Por el contrario, continuó un ritmo francamente descendente, revirtiéndose, de este modo, los diferenciales de rentabilidad. Los bajos niveles de la tasa de ganancia imperantes desde los noventa tienen a la economía asiática en una situación más o menos sostenida de estancamiento, con muy bajo crecimiento.

\section{Gráfica 1. Tasa de ganancia en Chile, Japón, Países Bajos y EU}

a) rotación estimada

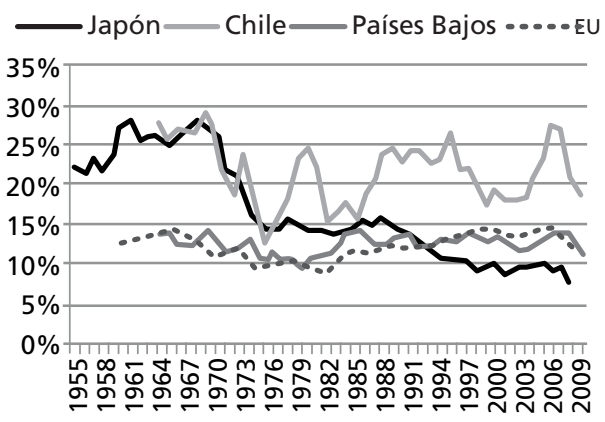

b) rotación anual

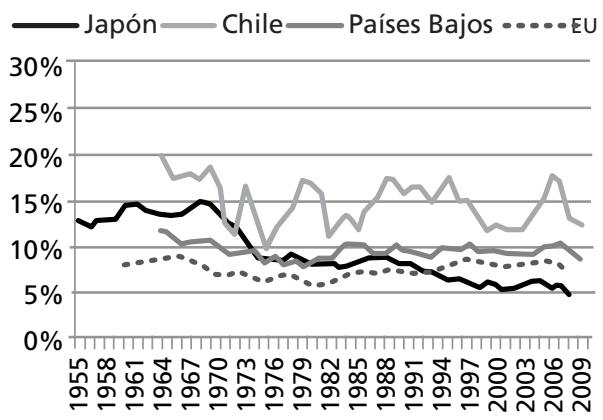

Fuente: Véase anexo 2.

En el caso chileno, el ciclo de descenso iniciado desde la posguerra alcanzó su punto mínimo en 1975. Hasta dicho año, la tasa de ganancia muestra una importante similitud con la japonesa. Luego de un breve interregno de recuperación de la rentabilidad, volvió a ubicarse en niveles mínimos a principios de los ochenta, en particular, en 1985. A partir de ahí la tasa de ganancia ingresó en un periodo más o menos sostenido de recuperación hasta 1995. El ciclo descendente que se dio en los años posteriores se interrumpió violentamente a partir de 2003, por el incremento de los precios internacionales del cobre, respecto a los cuales la rentabilidad del capital en Chile tiene una gran dependencia. ${ }^{12}$

Chile, en tanto país periférico, presenta un mayor nivel de rentabilidad. ${ }^{13}$ El caso de Japón es similar durante el periodo inicial de las series consideradas

\footnotetext{
${ }^{12}$ Respecto a la fuerte correlación entre la rentabilidad del capital chileno y los precios del cobre desde los años ochenta, véase Maito (2012).

${ }^{13}$ Un análisis comparativo de la rentabilidad en catorce países, y de la mayor rentabilidad en los países periféricos, puede consultarse en Maito (2014).
} 
en este estudio, etapa en la que difícilmente podría ser caracterizado como país central. Existiría, entonces, una dinámica en la cual el capital se expande en países de menor desarrollo relativo, los cuales presentarían mayores niveles de rentabilidad, de modo semejante al movimiento entre ramas.

Los Países Bajos muestran, en principio, menores niveles de rentabilidad y, sobre todo, en comparación con Chile, fluctuaciones mucho más acotadas. Se mantuvieron siempre en un rango de $10 \%$ a $15 \%$, hasta 1980 , con una tendencia descendente, mientras que en los años posteriores se observa una pequeña recuperación en relación al piso de los setenta. No obstante, el descenso de la tasa de ganancia en Japón fue tal que, durante los noventa, se convirtió en el país con menor tasa de ganancia de los cuatro. En EU, finalmente, el comportamiento de la rentabilidad, así como sus niveles, ha sido notablemente similar al de los Países Bajos, en tanto su condición compartida de países centrales. ${ }^{14}$

En la gráfica 1 puede observarse la comparación de los niveles de rentabilidad en el caso en que no se computa la rotación del capital, por lo que, naturalmente, son menores. Si bien no resulta afectado el sentido de la tendencia, se suaviza la pendiente de la misma, sobre todo en el caso japonés, en el que la tasa de ganancia es prácticamente el doble, si se toma en cuenta la rotación. Un punto destacable es la notable nivelación de la tasa de ganancia que se produce en los años más críticos del periodo 1974-1985 (en especial, de 1974 a 1976 y de 1982 a 1985).

La gráfica 2 presenta el promedio simple de la tasa de ganancia, su desviación estándar y la tasa de ganancia sin ajuste por rotación para los cuatro países. En general, la tasa de ganancia promedio se mantuvo estable hasta el final de los sesenta, cayendo luego de $20.7 \%$, en 1969 , a $11.8 \%$, en 1975 , lo que en definitiva implicó una reducción de dicha tasa de $42.9 \%$, entre esos años. Después, se dio una pequeña recuperación de la rentabilidad, alcanzando $14.7 \%$, valor inferior a todos los años anteriores a 1974, para luego volver a caer en 1982, a 12.3\%.

${ }^{14}$ Es importante realizar la siguiente aclaración sobre EU: en esta investigación, se considera capital fijo al stock neto de capital no residencial de cada economía, de modo que no se realiza ninguna discriminación entre el capital fijo público y privado. La mayor parte de las investigaciones, por no decir todas, sobre este tema en EU se concentran en el capital fijo y las ganancias del sector privado no financiero, dado que las series oficiales de stock de capital realizan una detallada desagregación hasta el año 1929. Por ello, los cálculos de esos trabajos muestran una caída desde niveles más altos que los presentados en este trabajo, reflejando la menor participación relativa del capital fijo privado en los sesenta y los setenta. Como en este trabajo se busca realizar una comparación internacional, se considera el capital fijo y las ganancias totales de la economía estadounidense. 
Gráfica 2. Promedio simple y desviación estándar de la tasa de ganancia, y promedio simple de la tasa de ganancia sin ajuste por rotación, 1964-2008

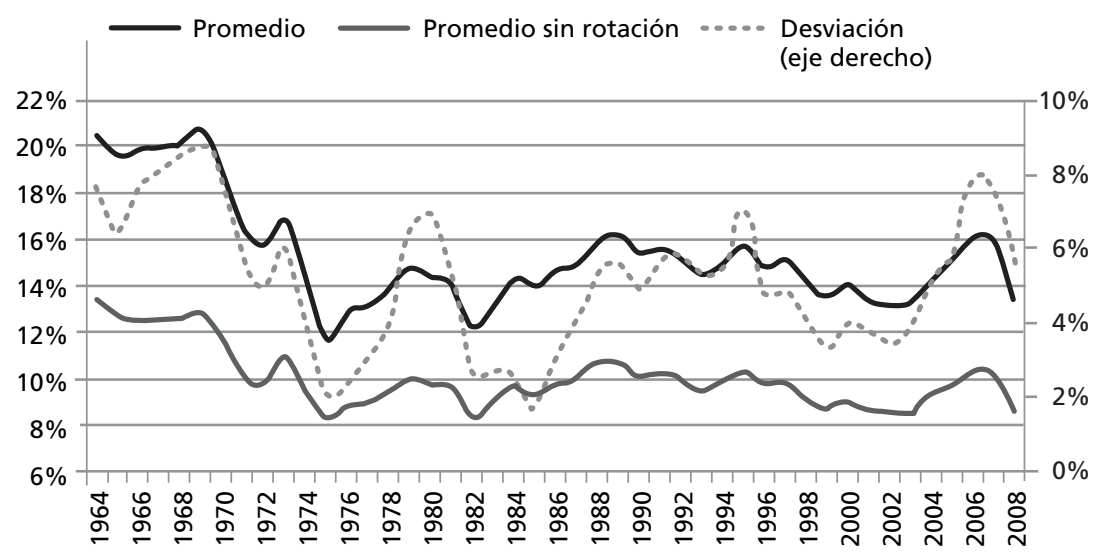

Fuente: Véase anexo 2.

En los términos de este trabajo, durante el ciclo de recuperación parcial de la rentabilidad, luego de 1982, la tasa de ganancia promedio se habría mantenido en un rango de $14 \%$ a $16 \%$, por debajo del promedio vigente en los sesenta, en torno a $20 \%$. La recuperación parcial de los niveles de rentabilidad desde mediados de los ochenta fue mayor en Chile que en EU y los Países Bajos, permaneciendo en declive la tasa japonesa (gráfica 1).

\section{LA ROTACIÓN DEL CAPITAL}

La rotación del capital representa el tiempo en el que el capital realiza todo su ciclo. La reducción de los tiempos de producción $\left(M \ldots P \ldots M^{\prime}\right)$ y circulación $\left(D-M, M^{\prime}-D\right)$ disminuye el tiempo en el que lleva a cabo su circuito, aumentando, por consiguiente, la velocidad y el número de rotaciones anuales. El desarrollo de la fuerza productiva y la escala de la producción tienen, de este modo, una fuerte correlación con el crecimiento de la velocidad de rotación (en la gráfica 3, se presentan las rotaciones estimadas y el producto interno bruto (PIB) per cápita de cada uno de los cuatro países estudiados).

Una mayor rotación implica que el capitalista puede disponer de su capital circulante adelantado en menos tiempo, pudiendo asignar una proporción mayor al capital fijo, y al propio capital circulante, expandiendo su volumen de producción (un capital que rote en la mitad del tiempo que otro de igual magni- 
Gráfica 3. Rotaciones anuales del capital circulante (izquierda) y PIB per cápita en dólares internacionales de 1990 (derecha)
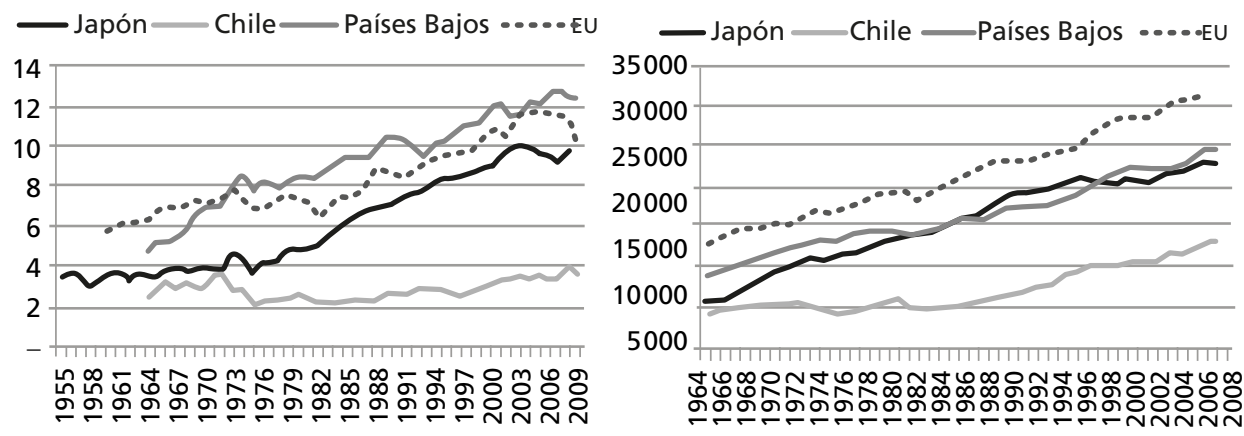

Fuente: Tablas de Maddison-Project (2013) y véase anexo 2.

tud puede utilizar, en definitiva, el doble de insumos y fuerza de trabajo). ${ }^{15}$ Una menor rotación representa un mayor nivel relativo de capital destinado a insumos y fuerza de trabajo hasta su recuperación mediante la venta. Y un descenso en la velocidad de rotación, como tiende a presentarse en años de crisis, durante los cuales las metamorfosis del capital se ven entorpecidas en sus distintas fases, implica la necesidad de fondos adicionales por parte de los capitalistas para lo-

${ }^{15}$ El capitalista debe mantener, en la forma de capital-dinero, buena parte del capital circulante que necesita adelantar durante el tiempo en el que su capital rota. Esto implica que si un capital rota en seis meses, el capitalista debe tener el capital-dinero necesario para el pago de fuerza de trabajo e insumos de medio año. No obstante, durante los primeros cinco meses, el capital-dinero destinado a los pagos del sexto mes no ingresará en la producción, por lo que el capitalista podrá, durante esos cinco meses, por ejemplo, colocarlo a interés. Según Marx (1968b, p. 251), “este capital-dinero está llamado a desempeñar un importante papel, tan pronto como se desarrolla el sistema de crédito, para convertirse, al mismo tiempo, en una de las bases de éste". Existe, también, una plétora de capital, con similar significación, que surge del desdoblamiento del tiempo de rotación en tiempo de producción y tiempo de circulación. Cuando una serie de mercancías producidas ingresan a la circulación, el capitalista debe disponer de este capital para mantener el flujo de producción, iniciando una nueva serie, mientras que la anterior se realiza en la circulación y termina su ciclo. Marx (1968a) afirma, en el tomo II de El capital, que la disponibilidad de capital, gracias al aumento de la velocidad de rotación que reduce el monto de capital circulante a adelantar, no necesariamente ampliará la escala, aumentando el capital fijo o circulante inicial. Por el contrario, este capital que se libera permanece como capital-dinero y es introducido en el propio mercado de dinero. Se trata de una plétora de dinero que surge por el acortamiento del periodo de rotación, sin afectar ni la escala de producción ni los precios, y que tampoco guarda relación con ningún crecimiento de la masa de dinero en circulación. Lo anterior constituye un punto a tener en cuenta como una fuente más de dinero que se canaliza al sector financiero, respecto a los ciclos de alto crecimiento del capital-dinero. 
grar completar el ciclo de valorización y reiniciarlo. ${ }^{16}$ La rotación es más alta en los Países Bajos, cuya tendencia a lo largo del ciclo se muestra, a grandes rasgos, lineal. Similar observación puede hacerse en el caso estadounidense, aunque la velocidad se incrementa en mayor medida durante los noventa. En Japón, existe también una tendencia ascendente de la rotación, aunque menos lineal: a partir de la segunda mitad de los años setenta crece en forma más marcada. Este rasgo diferencial ha sido, en mayor o menor medida, destacado desde otros puntos de vista como una exitosa gestión y reducción relativa de los inventarios propia del "toyotismo" japonés y la reducción de tiempo de circulación implícita.

Gráfica 4. Promedio simple de la tasa de ganancia y de la tasa de ganancia sin ajuste por rotación y tasa de ganancia como porcentaje de la tasa de ganancia sin ajuste, $1964-2008(1964=100)$

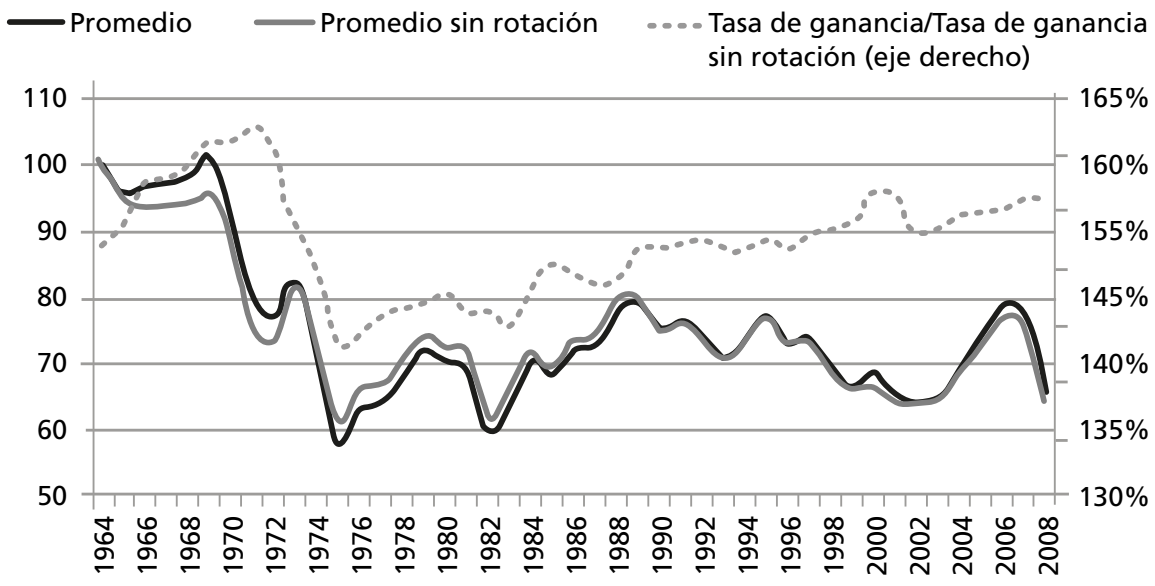

Fuente: Véase anexo 2.

En los cuatro casos, la crisis global de rentabilidad de los setenta se expresa en un estancamiento o descenso de la velocidad de rotación. En particular, de 1973 a 1975, se observan caídas que coinciden con las de la tasa de ganancia.

16 “Por el contrario, si el tiempo de circulación y, por tanto, el periodo de rotación, se alarga, se hará necesario proceder al desembolso de capital adicional, del bolsillo del propio capitalista, suponiendo que lo posea. Pero este capital se hallará invertido en una forma cualquiera, como parte del mercado de dinero; para que sea disponible, deberá desprenderse de su forma antigua, por ejemplo, vendiendo acciones o retirando depósitos, con lo cual se ejercerá también una acción indirecta sobre el mercado de dinero. O bien, deberá asumir aquella forma" (Marx, 1968b, p. 259). 
Puntualmente, entre 1970 y 1975 , esta tasa desciende a un ritmo promedio anual de $10.2 \%$, en Japón; $10.9 \%$, en Chile; 3.3\%, en Eu, y 4.5\%, en los Países Bajos. El número de rotaciones anuales del capital circulante se reduce de 4.66 a 3.78, en Japón (1973-1975); de 3.66 a 2.20, en Chile (1971-1976); de 7.87 a 6.72, en EU (1973-1975), y de 8.35 a 7.83, en los Países Bajos (1974-1975). ${ }^{17}$ En otros años críticos, por ejemplo 1982, 1990 o 2008, la velocidad de rotación del capital también disminuyó.

En la introducción del presente trabajo, se estableció que la estimación de la velocidad de rotación del capital circulante permitía una mayor aproximación a los niveles concretos de la tasa de ganancia, más allá de que las estimaciones sin ajuste por rotación o sobre capital fijo puedan ser indicadores útiles de la evolución de la rentabilidad. A este respecto, la gráfica 4 muestra tanto que la estimación de la tasa de ganancia ajustada por rotación no difiere demasiado en su evolución respecto de la tasa sin ajustar como que los niveles concretos de rentabilidad son en promedio 50\% mayores, una vez que se introduce la velocidad de rotación en la estimación. Naturalmente, en los años en los que la velocidad de rotación disminuye, la tasa de ganancia descenderá en mayor medida que la tasa sin ajustar, y viceversa.

\section{LA TASA SIMPLE Y LA TASA ANUAL DE PLUSVALÍA}

La tasa de plusvalía es definida por Marx (1968a) en el tomo I de El capital como la relación entre el tiempo de trabajo excedente y el tiempo de trabajo necesario para la reproducción de la fuerza de trabajo. En este sentido, la distribución del ingreso convencional expresaría la tasa de plusvalía, o explotación, como la relación entre el valor que se apropian los capitalistas y el valor de la fuerza de trabajo en términos monetarios (ganancias netas/masa salarial).

${ }^{17}$ La crisis general del capital en Chile, desde la primera mitad de los años setenta hasta buena parte de la década de los ochenta, se expresó en un descenso y un estancamiento pronunciado de la rotación. El desplazamiento de capitales desde sectores industriales predominantes en el periodo de posguerra hacia sectores, adicionales a la minería, más basados en recursos naturales, puede haber tenido, en este sentido, un efecto similar, si bien este flujo de capitales ha estado basado en una mayor rentabilidad relativa de dichos sectores. En el caso argentino, Iñigo (2007) estima la velocidad de rotación, basado en fuentes y estudios realizados en la década de los noventa, en 4.4 rotaciones anuales, como el promedio simple de las rotaciones estimadas por el autor para la agricultura (2.1) y la industria (6.6). La rotación del capital en Argentina tendría, entonces, un nivel mucho más emparentado con el de Chile, lo cual guarda correspondencia con el carácter periférico de ambos países y lo hasta aquí afirmado. 
En el tomo II de su obra, Marx (1968b) emprende el análisis de la rotación del capital, mientras que en el tomo III (Marx, 2012), en el que se ocupa del proceso de producción capitalista en su conjunto, considera la influencia de la rotación en los niveles de rentabilidad. Marx termina diferenciando, así, dos tasas de plusvalía. A la relación entre las ganancias y la masa salarial o capital variable consumido a lo largo del año la define como la tasa simple de plusvalía. Por otra parte, la tasa anual de plusvalía es definida como la relación entre las ganancias y el capital variable adelantado. Esta definición incorpora, de este modo, la rotación del capital en la determinación de la tasa de plusvalía. ${ }^{18}$

Suponiendo una proporción constante en el largo plazo, entre capital y trabajo, de 50/50, desde el punto de vista del proceso de producción, si la rotación del capital se elevase de uno a cinco rotaciones anuales, tendríamos que, a igual participación en el ingreso, los capitalistas obtendrían 50 adelantando 50, para luego obtener la misma proporción pero adelantando sólo 10, dado que en ese punto histórico el capital haría cinco rotaciones. Dicho esto, frente al aumento de la velocidad de rotación, que incide positivamente en la tasa anual de plusvalía, y a la composición orgánica del capital $(C C / C V)$ por el mayor gasto relativo en capital fijo, los salarios reales tienen, en cuanto costo, como capital variable adelantado, cada vez menor incidencia en la determinación de la tasa de ganancia, aunque obviamente la mantienen desde el punto de vista de la distribución del valor agregado entre trabajo y capital (gráfica 5). ${ }^{19}$

La tasa simple de plusvalía es igual a la tasa de plusvalía que en cada rotación obtiene el capital, pero luego de realizar varias rotaciones anuales, en las siguientes el valor de la fuerza de trabajo no representa un gasto adicional de

${ }^{18}$ Cabe destacar que en este trabajo se considera el excedente neto de explotación de las cuentas nacionales en el numerador de las tasas de plusvalía. Por otra parte, en la traducción al español de El capital publicada por el Fondo de Cultura Económica (Marx, 1968a; 1968b), los términos "cuota real de plusvalía" y "cuota anual de plusvalía" son equivalentes a "tasa simple de plusvalía" y "tasa anual de plusvalía". Del mismo modo, "capital desembolsado" y "capital empleado" son expresiones equivalentes a "capital adelantado" y "capital consumido" respectivamente.

${ }^{19}$ En una nota al pie del capítulo Xvi, "La rotación del capital variable", del tomo II de El capital (Marx, 1968b, p. 283), Engels menciona que el manuscrito contiene la siguiente nota que Marx planeaba desarrollar posteriormente: "Contradicción del régimen de producción capitalista: los obreros como compradores de mercancías son importantes para el mercado. Pero como vendedores de su mercancía - de la fuerza de trabajo, la sociedad capitalista tiende a reducirlos al minimum de su precio". Como se verá posteriormente, esta reducción al minimum quedará explicitada cuando se aborde la participación del capital variable adelantado en relación al PIB, que en los países centrales sólo representa en la actualidad aproximadamente 5\% del producto. No es casual que la citada nota, por otra parte, se encuentre en dicho capítulo. 
capital-dinero para el capitalista. En los términos distributivos ya ejemplificados, la tasa simple de plusvalía, que coincide con la lectura convencional de la distribución, es de 100\% (50/50). La tasa anual es, en cambio, del 500\% (50/10) al realizar cinco rotaciones. En cada ciclo la relación es igual a la tasa simple de plusvalía de $100 \%$ (10/10), pero como en las cuatro rotaciones subsiguientes a la inicial el capitalista se limita a reponer el mismo capital adelantado y recuperado, esas rotaciones no representan un capital adicional, obteniendo, sin embargo, una plusvalía de 10 en cada una de ellas (10/0).

La tasa simple de plusvalía (TSP) expresa, entonces, la relación entre dos flujos de valor creados por la fuerza de trabajo, el destinado a su reproducción ( $v$ ) y el apropiado por los capitalistas ( $p)$ a lo largo de un año. La tasa anual de plusvalía (TAP) expresa la relación entre el valor del capital variable adelantado (cv), valor que tiene para el capitalista poner en acción la fuerza de trabajo durante un ciclo completo, y el apropiado por los capitalistas $(p)$. En los términos de estos últimos, prescindiendo del resto de las condiciones, es la tasa anual de plusvalía la que representa su verdadero interés. ${ }^{20}$ Poco les importará una mayor tasa simple de plusvalía que, no obstante, se exprese en una tasa anual relativamente menor. Por el contrario, y comprendiendo la naturaleza del proceso de producción capitalista como proceso social y continuo, la tasa simple de plusvalía para un año, tal cual la vemos expresada en las estadísticas de distribución convencional entre capital y trabajo, es la resultante de determinada tasa anual de plusvalía, pero que, al considerar las cuentas nacionales simplemente los flujos del año, multiplica el capital variable adelantado por el número de rotaciones.

$$
T P S=\frac{p}{v}=\frac{g}{m S}=\frac{g}{c V(n)}=\frac{T P A}{n} \quad T P A=\frac{p}{c V}=\frac{g}{m s / n}=\operatorname{TPS}(n) .
$$

La explicación convencional de la mayor participación asalariada en los países centrales, que no considera la rotación del capital, conduce lógicamente a la conclusión de que en éstos es el nivel salarial, y la mayor organización del movimiento obrero, lo que explica los menores niveles de rentabilidad, estrangu-

\footnotetext{
${ }^{20}$ Marx suele presentar como un supuesto, para simplificar su exposición, que la tasa de plusvalía es de $100 \%$ (igual proporción ganancias/masa salarial) y que el capital rota una vez al año. Sin embargo, al tratar al capital ya no como el capital en general (Marx, 1968b), sino como varios capitales, los diferenciales de tasas de plusvalía y de velocidades de rotación cumplen un papel ineludible en el proceso social de valorización y en la distribución de la plusvalía entre los diferentes capitales (Marx, 2012).
} 
lando las ganancias (profit squeeze). No obstante, la propia tasa de plusvalía es, en general, mayor en estos países cuando se introduce la rotación en el cálculo, como tasa anual y relación plusvalor/capital variable adelantado. ${ }^{21}$ De esta forma, es en los países centrales donde las ganancias para los capitalistas son más holgadas respecto a su capital variable adelantado o al producto. Dado que las tesis sobre el estrangulamiento de las ganancias proponen que es el mayor costo laboral el que explica el descenso de la rentabilidad, se debe considerar este costo no como el flujo anual de salarios (como, de hecho, sostienen dichas tesis), sino como el capital variable realmente adelantado, como el costo verdadero que tiene para el capitalista el consumo productivo de la fuerza de trabajo. Más adelante se verá que este costo no sólo es sistemáticamente menor en los países centrales, sino que presentó una tendencia descendente en EU y los Países Bajos durante los años sesenta y principios de los setenta, cuando el estrangulamiento de las ganancias se habría gestado y la participación asalariada en el ingreso mostraba cierto crecimiento. Como se verá a continuación, en el caso de los países centrales, esta mayor tasa de plusvalía es contrarrestada por una mayor proporción entre capital constante y variable, una mayor composición orgánica, que en definitiva resulta en menores niveles de rentabilidad.

En las décadas de posguerra, pareciera existir en las tasas de plusvalía (gráfica 5) un diferencial similar al de las tasas de ganancia (gráfica 1). La mayor

\section{Gráfica 5. Tasa de plusvalía}

a) rotación estimada

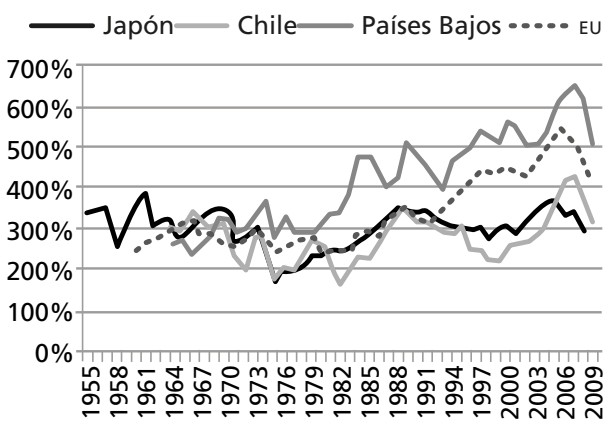

b) rotación anual

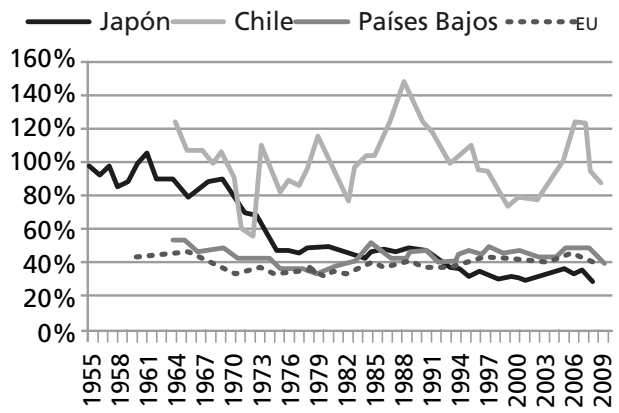

Fuente: Véase anexo 2.

${ }^{21}$ Martínez y Valle (2011) se ocupan, explícitamente, de analizar los diferenciales de las tasas de plusvalía entre países periféricos y países centrales, considerando la tasa de plusvalía sin rotación. A partir de dicho supuesto, concluyen que "la tasa de plusvalía en los países subdesarrollados es más alta que en los países desarrollados, contrariamente a lo que podría asumirse de acuerdo a la teoría". Esto sería correcto sólo en el caso de la tasa simple de plusvalía. 
nivelación en las tasas de plusvalía se da en este caso, principalmente a mitad de los setenta. A partir de los ochenta se observa un cambio: los diferenciales en las tasas de plusvalía a favor de Chile y Japón que tendían a predominar se invierten, sobre todo en los años noventa. ${ }^{22}$

\section{LA DISTRIBUCIÓN DEL INGRESO COMO EXPRESIÓN DEL PROCESO DE PRODUCCIÓN CAPITALISTA}

El nivel de participación de los trabajadores en el ingreso surge como el porcentaje que es apropiado como salario por los mismos. El cálculo se realiza a partir de la estimación de la masa salarial, expresada en su forma más simple como la multiplicación del salario nominal anual promedio por el número de asalariados. $\mathrm{O}$, en términos marxianos, como el capital variable consumido por trabajador, multiplicado por el número de asalariados.

Adicionalmente, debe introducirse como denominador, para el cálculo de la participación, el producto nominal. De esta forma, un menor o mayor crecimiento relativo de un componente afecta la participación. La distribución es la expresión final de lo que, en primer lugar, acontece en la esfera de la producción. Es ésta la que determina la distribución primaria y funcional del ingreso.

En la producción, los salarios forman parte del capital variable adelantado por el capitalista, pero este capital no es necesariamente igual al capital variable consumido o masa salarial. Esta igualación, que supone una sola rotación anual -ya sea por obedecer a una cierta concepción ideológico-económica, ya sea por falta de datos, o por ausencia del cálculo de la rotación- no afecta los niveles de participación, pero, a fines de explicar ésta como resultado del ámbito específico de la producción capitalista, debe introducirse en el cálculo la rotación.

${ }^{22} \mathrm{Si}$ bien son cuestiones que quedan fuera del alcance de este trabajo, cabe resaltar la importancia de realizar un análisis más detallado de los factores determinantes de las variables. Por ejemplo, la tasa de plusvalía chilena, desde los setenta, mantiene un nivel muy semejante al de la japonesa, salvo por tres periodos en los que crece a mayor ritmo. En dos de éstos, el mayor crecimiento se relaciona con el pago de la fuerza de trabajo por debajo de su valor, en el marco de agudas crisis que operaron una desvalorización general del capital chileno y de todas las variables del proceso productivo. Así, esa mayor tasa de plusvalía, que en el corto plazo se reflejó en un alza de la tasa de ganancia, se da a expensas no sólo del pago de la fuerza de trabajo por debajo de su valor, sino de una reducción de la escala del capital chileno, de modo que ese crecimiento de la rentabilidad se da a expensas de una reducción sustancial de la masa de ganancias, producto de la crisis (véase datos de Chile en el anexo 1). 
Introduciendo la rotación del capital como fenómeno propio de la producción capitalista, se obtiene otra determinación de los niveles de participación asalariada. El cálculo de la masa salarial ya no surge exclusivamente de la multiplicación del salario anual por el número de asalariados, sino del capital variable adelantado por trabajador multiplicado por el número de rotaciones y de asalariados:

$$
\frac{M S}{Y}=\frac{\text { salario anual promedio (asalariados })}{Y}=\frac{(C V \text { por asalariado })(N) \text { (asalariados })}{Y} .
$$

Naturalmente, la participación de las ganancias surge de multiplicar el numerador de la última ecuación por la tasa anual de plusvalía:

$$
\frac{G}{Y}=\frac{(C V A \text { por asalariado) }(N) \text { (asalariados) (tasa anual de plusvalía) }}{Y} .
$$

Es el mayor desarrollo del capital y la fuerza productiva, que naturalmente requiere o genera mayores niveles de capacitación u organización a partir de su propia escala, el que opera un mayor abaratamiento relativo de la fuerza de trabajo (mayor tasa anual de plusvalía y rotación) desde el punto de vista del proceso capitalista de producción. La lectura convencional de los diferenciales de participación asalariada entre países desarrollados y países en desarrollo suele centrarse así en los diferentes niveles salariales (y de capacitación) requeridos por la complejidad que alcanza el desarrollo productivo o el mayor nivel de organización que a nivel general tiene la clase trabajadora en uno y otro conjunto de países. En ambas interpretaciones se da por sentado que la mayor participación en el ingreso brota, en definitiva, de un mayor costo laboral relativo para el capital de cada país, sea por requerimientos productivos o por niveles de organización político-sindical -los cuales, en realidad, se presentan en forma simultánea- que reducen la participación de las ganancias en el ingreso. Los capitalistas obtendrían en los países desarrollados una ganancia relativa menor por cada salario abonado.

Si se considera la distribución a partir de todos los elementos de la producción capitalista, surge un cuadro diferente. La mayor rotación del capital, que incluye obviamente el capital variable adelantado, en los países desarrollados invierte completamente las apariencias que surgen a partir de la distribución convencional del ingreso. El costo laboral relativo, expresado también como porcentaje del ingreso, es claramente menor en estos países. Los mayores niveles de participación asalariada se conforman a partir de menores costos relativos, tam- 
bién en relación al capital fijo o la composición, y mayor cantidad de rotaciones anuales. De este modo, en los países centrales la relación $C V / Y$ es menor que en los países periféricos, tal como aparece en la gráfica $6 .{ }^{23}$

Gráfica 6. Masa salarial (izquierda) y capital variable adelantado (derecha) como porcentajes del PIB a precios de mercado
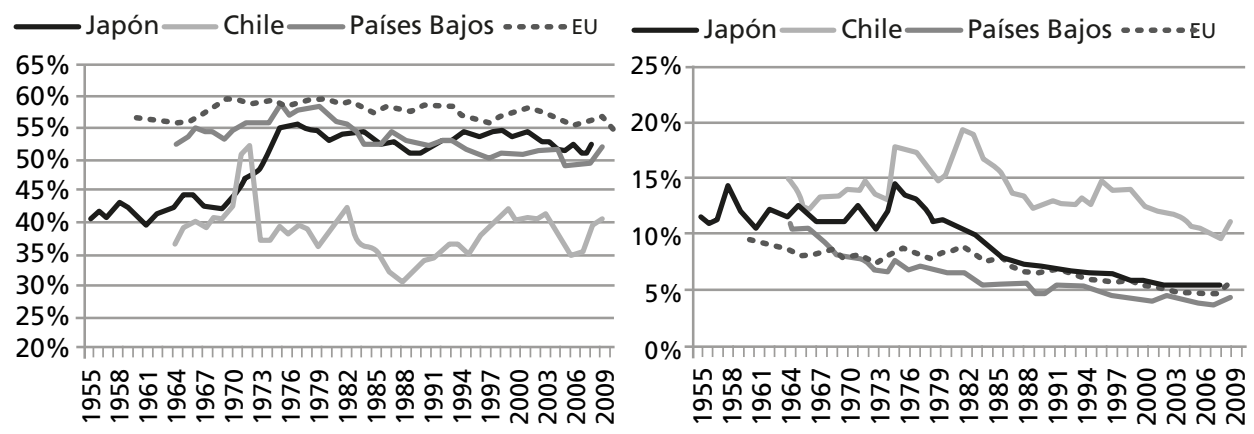

Fuente: Véase anexo 2.

En definitiva, existe otra forma de expresar la participación de las ganancias y los salarios en el ingreso que da un paso más y considera la tasa anual de plusvalía. Y dado que las ganancias son una función de la tasa anual de plusvalía y el capital variable adelantado, la distribución del ingreso puede ser expresada directamente como resultante del número de rotaciones y la tasa anual de plusvalía, anulando el capital variable presente en los tres términos:

$$
\frac{M S}{Y}=\frac{M S}{M S+G}=\frac{(C V)(N)}{(C V)(N)+G}=\frac{(C V)(N)}{(C V(N))+(C V(T P A))}=\frac{N}{N+T P A} .
$$

Ahora, la distribución aparece como expresión del proceso de valorización y como función de la tasa anual de plusvalía y la rotación del capital. No se trata de una forma entre tantas de presentar los datos referidos a la distribución, sino de expresar cabalmente los factores determinantes productivos de la cual es

${ }^{23}$ Destaca el caso chileno, en el que el brutal ajuste social llevado a cabo luego del golpe de Estado de Augusto Pinochet no sólo no logró revertir la crisis de rentabilidad, sino que tampoco lograría, hasta la crisis de 1982, reducir los costos laborales de los capitalistas en virtud del derrumbe de los niveles de actividad y la propia velocidad de rotación. Una conclusión similar acerca del fracaso de la dictadura argentina en restablecer los niveles previos de rentabilidad, a pesar de un brutal ajuste social, puede encontrarse en Maito (2015). 
resultante. ${ }^{24}$ Así, una distribución puede aparecer constante en apariencia, aunque sus componentes internos se modifiquen. Y si es el caso, ¿en qué sentido varían? En el de una caída del costo de la fuerza de trabajo $(\mathrm{CV})$, entendido ya no como equivalente a cierta cantidad de bienes, sino como el costo real que tiene para los capitalistas el consumo productivo de esta fuerza a lo largo de una rotación.

\section{Cuadro 1. Ciclo del capital variable y categorías económicas con base en una y seis rotaciones $(\mathrm{N})$ anuales}

\begin{tabular}{|c|c|c|c|c|c|c|c|c|c|c|c|c|}
\hline$N=1$ & 1 & 2 & 3 & 4 & 5 & 6 & 7 & 8 & 9 & 10 & 11 & 12 \\
\hline A & \multicolumn{12}{|c|}{ Tiempo de producción y circulación por circuito del capital (TPTC) } \\
\hline B & \multicolumn{6}{|c|}{$\begin{array}{l}\text { Capital variable adelantado por circuito } \\
\text { del capital (CVA-I) }\end{array}$} & \multicolumn{6}{|c|}{ Plusvalía por circuito del capital $(P-l)$} \\
\hline c & \multicolumn{12}{|c|}{ Tiempo de Trabajo / Valor Agregado (TT/VA) } \\
\hline D & \multicolumn{6}{|c|}{ Tiempo de trabajo necesario (TTN) } & \multicolumn{6}{|c|}{ Tiempo de trabajo excedente (TTE) } \\
\hline $\mathrm{E}$ & \multicolumn{6}{|c|}{ Masa salarial } & \multicolumn{6}{|c|}{ Ganancias } \\
\hline $\mathrm{F}$ & \multicolumn{6}{|c|}{ Capital variable adelantado (CVA) } & \multicolumn{6}{|c|}{ Plusvalía $(P)$} \\
\hline$N=6$ & 1 & 2 & 3 & 4 & 5 & 6 & 7 & 8 & 9 & 10 & 11 & 12 \\
\hline A & \multicolumn{12}{|c|}{ TPTC } \\
\hline B & CVA-I & $P-I$ & CVA-II & $P-l l$ & CVA-III & $P-I I I$ & CVA-IV & $P-I V$ & CVA-V & $P-V$ & CVA-VI & $P-\mathrm{VI}$ \\
\hline c & \multicolumn{12}{|c|}{ Tiempo de trabajo/valor agregado (TT/VA) } \\
\hline $\mathrm{D}$ & \multicolumn{6}{|c|}{ Tiempo de trabajo necesario $(T T N)$} & \multicolumn{6}{|c|}{ Tiempo de trabajo excedente (TTE) } \\
\hline E & \multicolumn{6}{|c|}{ Masa salarial } & \multicolumn{6}{|c|}{ Ganancias } \\
\hline $\mathrm{F}$ & CVA-I & & & $P-I$ & a $P-V I$ & & & & & & & \\
\hline
\end{tabular}

En este sentido, no debe generarse la falsa impresión de que la unidad propia del proceso es el año natural. La unidad propia del proceso es el tiempo de rotación del capital circulante, considerados sus tiempos de producción y circulación (fila A del cuadro 1). La división de la masa salarial entre el número de rotaciones al año es, en este sentido, sólo una operación analítica a posteriori a partir de estadísticas construidas sobre una base anual. El proceso, en realidad, ha sido el de una reducción persistente de los tiempos de producción y circula-

\footnotetext{
24 "La cuota anual de plusvalía o la comparación entre la plusvalía producida durante el año y el capital variable desembolsado en su conjunto (a diferencia del capital variable que refluye durante el año) no es, por tanto, nada subjetivo, sino que es la dinámica real del capital la que engendra por si misma esta contraposición" (Marx, 1968b, p. 274).
} 
ción por el desarrollo de la fuerza productiva, que ha implicado que el tiempo requerido para completar la rotación del capital circulante se fuera reduciendo desde, por ejemplo, un año a dos meses.

La unidad natural cronológica es el propio capital completando su circuito en un tiempo cada vez más reducido, gracias al impulso que imprime al desarrollo de las fuerzas productivas, que resulta en una reducción del tiempo de trabajo socialmente necesario para la producción de mercancías, comprendidos sus tiempos de producción y circulación. El capital variable adelantado, como porcentaje del PIB, presenta una tendencia claramente descendente y una divergencia creciente de la participación asalariada total, conforme aumenta la velocidad de rotación, y la tasa anual de plusvalía (véase la gráfica 5).

El costo laboral real que enfrentan los capitalistas en los países centrales representó en 2008 sólo entre 4\% y 5.4\% del PIB a precios de mercado, mientras que, por otra parte, la masa salarial, o capital variable consumido, se ubicó entre $49.6 \%$ y $56.5 \%$. La consolidación de elevados niveles de participación en el caso japonés coincide con un descenso sostenido del costo laboral de la fuerza de trabajo, el cual se ha reducido prácticamente en dos tercios desde el pico alcanzado en 1975.

En el caso chileno, en tanto país periférico con un desarrollo de las fuerzas productivas inferior, la participación asalariada es menor y, simultáneamente, el costo laboral mayor, entendiendo este último como el costo que tiene para los capitalistas el consumo productivo de la fuerza de trabajo y no como una canasta de bienes de consumo en particular. Mediante el aumento de la velocidad de rotación del capital variable, el incremento de su tasa anual de plusvalía (fila F del cuadro 1) se desliga del tiempo anual absoluto que requiere trabajar para sí la clase obrera (fila D) y, por otra parte, dicho incremento no se contradice con una reducción absoluta de la demanda social solvente representada por el consumo masivo de la clase obrera (fila E).

En tanto que el éxito de la valorización de cualquier capital se rige por su rentabilidad, es decir por la magnitud de la valorización lograda respecto al valor inicial, los límites que enfrenta el incremento de la productividad para la reducción del tiempo necesario considerado como jornada laboral no son los mismos que encuentra para la reducción del tiempo necesario considerado como capital variable adelantado. El éxito de la valorización respecto al trabajo vivo ya no se mide simplemente como una proporción entre tiempo de trabajo necesario y tiempo excedente sobre un periodo anual (fila D del cuadro 1) sino como capital variable adelantado y plusvalor (fila $\mathrm{F}$ ). 
La reducción del tiempo total de trabajo necesario que realiza la fuerza de trabajo en la producción, sea con salarios reales crecientes o decrecientes, disminuye la participación de éstos en el consumo, afectando las posibilidades de realización del valor de las mercancías, toda vez que el consumo de los capitalistas en ningún modo podría cubrir esa merma relativa. La producción general de mercancías del régimen capitalista se caracteriza justamente por la conformación de una clase obrera despojada de medios de producción que es, por otra parte, consumidora masiva de las mercancías que produce, también, en forma masiva.

Incrementando la velocidad de rotación, el éxito de su valorización en cuanto a la rentabilidad -0 , más concretamente, en cuanto a su tasa de plusvalía- se divorcia parcialmente del tiempo de trabajo necesario y, simultáneamente, propicia una demanda social solvente del producto social que no afecta en mayor medida su verdadero costo laboral, el monto del capital variable adelantado. De este modo, el capital variable adelantado puede, incluso, descender en conjunto con una masa salarial ascendente (reducción de la tasa de plusvalía simple e incremento de la demanda social solvente de los obreros).

El capital se asegura así las condiciones de su valorización en cuanto a rentabilidad y demanda social solvente. Este incremento en la velocidad de rotación del capital circulante no es un recurso extraño o externo al capital, sino que está contemplado en su propio desarrollo. Es, no obstante, un aspecto que Marx probablemente no abordó del todo en su obra (en cuanto a las implicaciones señaladas) y que, por otra parte, pocos autores posteriores han abordado.

\section{LA COMPOSICIÓN ORGÁNICA DEL CAPITAL}

En los términos de Marx (1968a, pp. 625-632), los capitalistas tienden a invertir relativamente más en capital constante que en capital variable. Obligados por la competencia que encuentran en otros capitales, el aumento de la productividad o de su fuerza productiva, les permite eventualmente vender a un menor valor que sus competidores y abarcar mayores cuotas de mercado, o por lo menos, mantener el valor de sus mercancías en niveles socialmente aceptados y sostenerse como capitales en funciones. La reducción del valor de las mercancías tiene también el efecto potencial de abaratar el valor de reproducción de la fuerza de trabajo.

Es este crecimiento relativo del capital constante respecto al capital variable - es decir, la fuerza de trabajo, que es la fuente de la plusvalía- el que explica en última instancia la tendencia descendente de la tasa de ganancia, incluso 
ante aumentos en la tasa de plusvalía. La composición de valor del capital expresa, cuando se considera la rotación, la relación entre los montos que el capitalista adelanta en capital constante y en capital variable, que reflejan la verdadera estructura de costos de su capital total adelantado. Si no se toma en cuenta la rotación, lo que se obtiene es un flujo o una estructura de gastos realizados, pero que en el caso del capital circulante, y particularmente el variable, no pueden ser considerados como el verdadero costo que enfrenta el capitalista.

\section{Gráfica 7. Composición de valor del capital}

a) rotación estimada

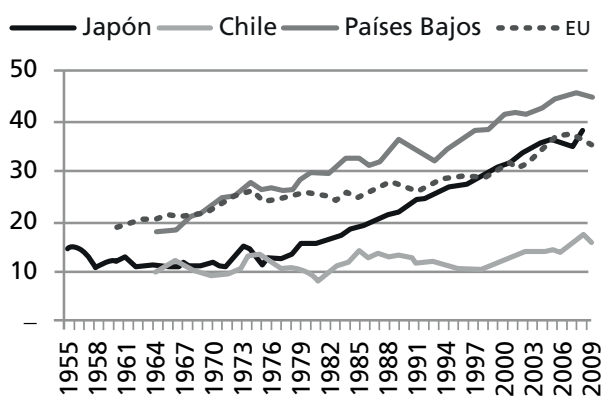

b) rotación anual

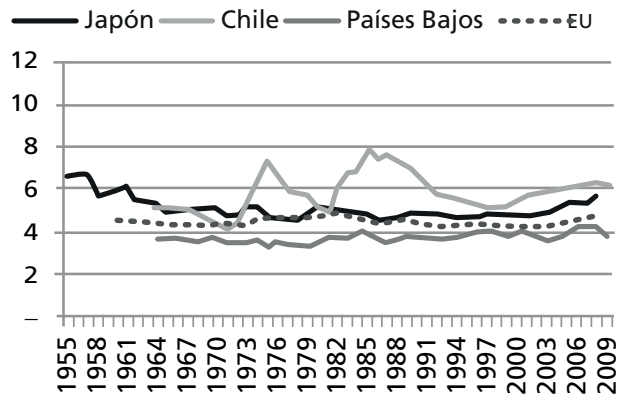

Fuente: Véase anexo 2.

Al igual que en los casos anteriores, la rotación del capital modifica sustancialmente el cuadro ofrecido por el supuesto de una rotación anual, como se observa en la gráfica 7. La composición de valor es mayor en los países centrales. En los casos Eu y países bajos la tasa de plusvalía describe una tendencia similar, las tasas de ganancia se mantienen relativamente estables. En el caso japonés, la tasa de plusvalía no ha logrado acompañar el crecimiento de la composición $\mathrm{y}$, en consecuencia, la rentabilidad se ha mantenido descendente en las últimas décadas. En Chile, la composición es, en general, menor, en buena medida debido a la menor rotación que afecta al capital variable adelantado, manteniendo un importante diferencial de rentabilidad respecto a los otros tres países. La composición orgánica del capital, síntesis de las composiciones técnica y de valor, tiende a ser menor en relación a capitales con rotación más elevada. ${ }^{25} \mathrm{En}$ este caso, la composición de valor ajustada por rotación nos indica los verdaderos requerimientos relativos de capital a invertir para iniciar y concluir un ciclo,

\footnotetext{
${ }^{25}$ La composición orgánica del capital se expresa tanto en el volumen de capital constante empleado por trabajador (composición técnica) como en la relación que hay entre el monto del capital constante y el capital variable (composición de valor), mayores conforme se desarrolla la fuerza productiva.
} 
Gráfica 8. Participación del capital constante fijo (CCF), el capital constante circulante (CCC) y el capital variable (CV) en el capital total adelantado, y participación del capital constante fijo en el capital total adelantado sin ajuste por rotación (CCF-n1)
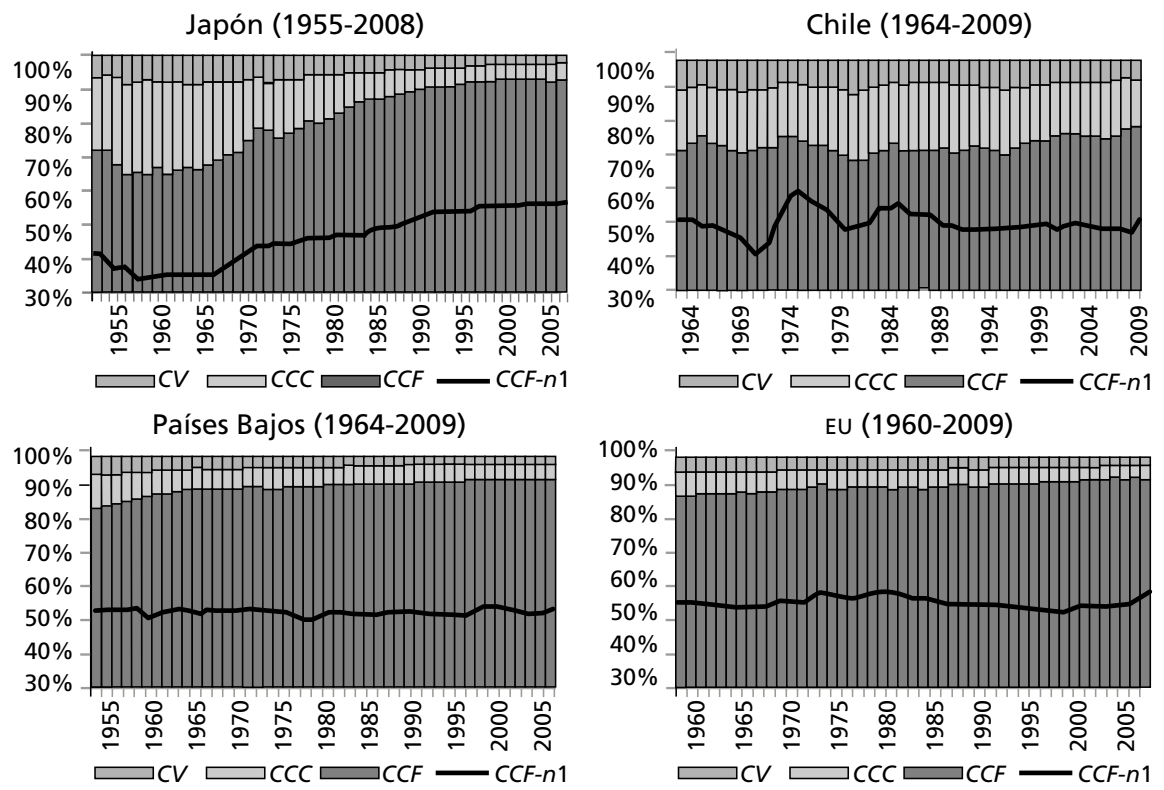

Fuente: Véase anexo 2.

en definitiva, para actuar como capitalista. En los dos casos -el estadounidense y el chileno- de menor crecimiento de la composición, ésta prácticamente se ha duplicado desde 1964, lejos del cuadro de relativa estabilidad y menores niveles que surgirían de una estimación sin ajuste por rotación.

Como se observa en la gráfica 8 , la participación del capital fijo en el capital total adelantado es predominante y tiende a incrementarse. Incluso, existe una importante convergencia en los niveles alcanzados por la participación del capital fijo en Eu, Países Bajos y Japón. Luego del incremento de la participación de éste, en la posguerra, desde la década de los noventa, los diferenciales entre estos tres países en la participación son mínimos, con niveles superiores a 90\% del capital total adelantado. En Chile, la participación del capital fijo es menor y más estable. Naturalmente, la mayor participación relativa del capital variable implica una menor composición orgánica y, finalmente, mayores niveles de rentabilidad. Dado el papel predominante del capital fijo en el capital adelantado, el nivel de la tasa de ganancia se encontrará, así, crecientemente vinculado al de la tasa de ganancia sobre capital fijo. 


\section{Conclusiones}

A lo largo del presente trabajo se analizó la rotación, principalmente del capital circulante, de acuerdo a lo desarrollado por Marx (1968b) en el tomo II de El capital y se realizaron también estimaciones aproximadas de la velocidad de rotación del capital circulante para los casos de cuatro países. A nivel general, dicha velocidad se incrementó en forma clara, con algunos retrocesos en lapsos críticos, entre los que destacan la segunda mitad de los setenta y los inicios de los ochenta.

La introducción de la velocidad de rotación en el análisis evidencia mayores niveles de rentabilidad, composición orgánica del capital y tasa de plusvalía respecto a los que surgirían de simples estimaciones sin su correspondiente ajuste por el número de rotaciones al año. En el periodo estudiado, se diferencian dos etapas. La primera, que en rigor se inicia en los cincuenta, esta marcada por un fuerte descenso de la rentabilidad, común a los cuatro países. Tras la crisis de 1982, salvo en el caso japonés, existe una recuperación de la tasa de ganancia.

La introducción de la velocidad de rotación en el cálculo de las variables modifica en parte las visiones convencionales referidas a la forma en la que se establecen determinados niveles de participación en el ingreso en el marco de una economía capitalista. Dada la influencia de la velocidad de rotación, existe cierta divergencia entre la participación asalariada y la participación del capital variable adelantado, el cuál tiende a reducirse a un mínimo como porcentaje del valor agregado. Los niveles convencionales de participación asalariada, que relacionan la masa salarial y el ingreso en términos de las cuentas nacionales, se establecen en el marco de procesos de producción capitalistas al interior de un periodo anual de sucesivas rotaciones del capital.

\section{Anexo 1}

Cuadro 1.1. Japón, 1955-2008 (continúa)

\begin{tabular}{|c|c|c|c|c|c|c|c|c|c|}
\hline & 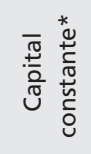 & 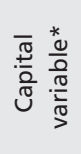 & 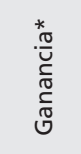 & 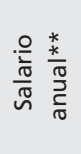 & 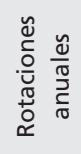 & 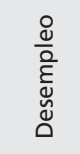 & 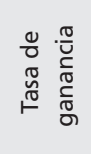 & 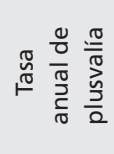 & 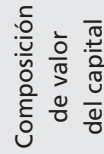 \\
\hline 1955 & 15221 & 1048 & 3625 & 3697 & 3.5 & $2.5 \%$ & $22.3 \%$ & $345.9 \%$ & 14.5 \\
\hline 1956 & 15518 & 1014 & 3551 & 3829 & 3.8 & $2.3 \%$ & $21.5 \%$ & $350.4 \%$ & 15.3 \\
\hline 1957 & 15204 & 1091 & 3820 & 3900 & 3.6 & $1.9 \%$ & $23.4 \%$ & $350.2 \%$ & 13.9 \\
\hline 1958 & 14798 & 1355 & 3524 & 4059 & 3.0 & $2.1 \%$ & $21.8 \%$ & $260.1 \%$ & 10.9 \\
\hline 1959 & 14945 & 1259 & 3859 & 4314 & 3.4 & $2.2 \%$ & $23.8 \%$ & $306.5 \%$ & 11.9 \\
\hline 1960 & 15871 & 1310 & 4702 & 4689 & 3.6 & $1.7 \%$ & $27.4 \%$ & $359.0 \%$ & 12.1 \\
\hline
\end{tabular}


Cuadro 1.1. Japón, 1955-2008 (concluye)

\begin{tabular}{|c|c|c|c|c|c|c|c|c|c|}
\hline & 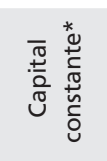 & 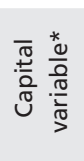 & $\begin{array}{l}* \\
.0 \\
\frac{\pi}{U} \\
\frac{C}{1} \\
\frac{0}{0} \\
\frac{0}{0}\end{array}$ & $\frac{0}{\frac{0}{\frac{1}{T}}} \frac{*}{\frac{*}{\pi}}$ & 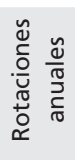 & 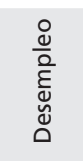 & 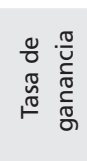 & 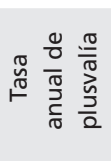 & 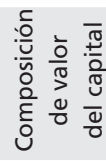 \\
\hline 1961 & 18058 & 1399 & 5471 & 5250 & 3.8 & $1.4 \%$ & $28.1 \%$ & $391.1 \%$ & 12.9 \\
\hline 1962 & 19489 & 1724 & 5456 & 5908 & 3.4 & $1.3 \%$ & $25.7 \%$ & $316.4 \%$ & 11.3 \\
\hline 1963 & 21049 & 1857 & 5977 & 6620 & 3.6 & $1.3 \%$ & $26.1 \%$ & $321.8 \%$ & 11.3 \\
\hline 1964 & 22930 & 2001 & 6531 & 7375 & 3.7 & $1.1 \%$ & $26.2 \%$ & $326.4 \%$ & 11.5 \\
\hline 1965 & 23856 & 2289 & 6518 & 8105 & 3.5 & $1.2 \%$ & $24.9 \%$ & $284.7 \%$ & 10.4 \\
\hline 1966 & 25469 & 2367 & 7160 & 8762 & 3.7 & $1.3 \%$ & $25.7 \%$ & $302.5 \%$ & 10.8 \\
\hline 1967 & 28073 & 2459 & 8309 & 9525 & 3.9 & $1.3 \%$ & $27.2 \%$ & $337.9 \%$ & 11.4 \\
\hline 1968 & 30393 & 2725 & 9313 & 10388 & 3.8 & $1.2 \%$ & $28.1 \%$ & $341.7 \%$ & 11.2 \\
\hline 1969 & 34071 & 2964 & 10249 & 11464 & 3.9 & $1.1 \%$ & $27.7 \%$ & $345.8 \%$ & 11.5 \\
\hline 1970 & 38527 & 3260 & 10921 & 12705 & 3.9 & $1.1 \%$ & $26.1 \%$ & $335.0 \%$ & 11.8 \\
\hline 1971 & 42534 & 3803 & 10165 & 14271 & 3.8 & $1.2 \%$ & $21.9 \%$ & $267.3 \%$ & 11.2 \\
\hline 1972 & 54854 & 4421 & 12595 & 18140 & 4.1 & $1.4 \%$ & $21.2 \%$ & $284.9 \%$ & 12.4 \\
\hline 1973 & 74475 & 4939 & 15290 & 23038 & 4.7 & $1.3 \%$ & $19.3 \%$ & $309.5 \%$ & 15.1 \\
\hline 1974 & 80945 & 5603 & 13907 & 24776 & 4.4 & $1.4 \%$ & $16.1 \%$ & $248.2 \%$ & 14.4 \\
\hline 1975 & 80653 & 6852 & 12571 & 25896 & 3.8 & $1.9 \%$ & $14.4 \%$ & $183.5 \%$ & 11.8 \\
\hline 1976 & 83801 & 6561 & 13355 & 27155 & 4.1 & $2.0 \%$ & $14.8 \%$ & $203.5 \%$ & 12.8 \\
\hline 1977 & 93593 & 7392 & 14693 & 31019 & 4.2 & $2.0 \%$ & $14.6 \%$ & $198.8 \%$ & 12.7 \\
\hline 1978 & 120538 & 9021 & 20139 & 39647 & 4.4 & $2.2 \%$ & $15.5 \%$ & $223.2 \%$ & 13.4 \\
\hline 1979 & 118160 & 7650 & 18723 & 37238 & 4.9 & $2.1 \%$ & $14.9 \%$ & $244.7 \%$ & 15.4 \\
\hline 1980 & 116571 & 7347 & 17364 & 34724 & 4.7 & $2.0 \%$ & $14.0 \%$ & $236.3 \%$ & 15.9 \\
\hline 1981 & 112542 & 6917 & 17174 & 34766 & 5.0 & $2.2 \%$ & $14.4 \%$ & $248.3 \%$ & 16.3 \\
\hline 1982 & 97146 & 5854 & 14474 & 30200 & 5.2 & $2.4 \%$ & $14.1 \%$ & $247.3 \%$ & 16.6 \\
\hline 1983 & 97729 & 5677 & 14315 & 31194 & 5.5 & $2.6 \%$ & $13.8 \%$ & $252.2 \%$ & 17.2 \\
\hline 1984 & 97484 & 5257 & 14437 & 31292 & 6.0 & $2.7 \%$ & $14.1 \%$ & $274.6 \%$ & 18.5 \\
\hline 1985 & 96730 & 5049 & 15143 & 31279 & 6.2 & $2.6 \%$ & $14.9 \%$ & $299.9 \%$ & 19.2 \\
\hline 1986 & 134593 & 6766 & 21558 & 44471 & 6.6 & $2.8 \%$ & $15.3 \%$ & $318.6 \%$ & 19.9 \\
\hline 1987 & 157876 & 7539 & 24820 & 51528 & 6.8 & $2.8 \%$ & $15.0 \%$ & $329.2 \%$ & 20.9 \\
\hline 1988 & 178864 & 8290 & 28936 & 58055 & 7.0 & $2.5 \%$ & $15.5 \%$ & $349.1 \%$ & 21.6 \\
\hline 1989 & 173446 & 7724 & 26464 & 54001 & 7.0 & $2.3 \%$ & $14.6 \%$ & $342.6 \%$ & 22.5 \\
\hline 1990 & 169926 & 7285 & 24912 & 51853 & 7.1 & $2.1 \%$ & $14.1 \%$ & $342.0 \%$ & 23.3 \\
\hline 1991 & 183972 & 7551 & 26227 & 56205 & 7.4 & $2.1 \%$ & $13.7 \%$ & $347.4 \%$ & 24.4 \\
\hline 1992 & 195390 & 7810 & 25212 & 58917 & 7.5 & $2.2 \%$ & $12.4 \%$ & $322.8 \%$ & 25.0 \\
\hline 1993 & 217469 & 8391 & 26406 & 66005 & 7.9 & $2.5 \%$ & $11.7 \%$ & $314.7 \%$ & 25.9 \\
\hline 1994 & 233948 & 8719 & 26745 & 71252 & 8.2 & $2.9 \%$ & $11.0 \%$ & $306.7 \%$ & 26.8 \\
\hline 1995 & 250813 & 9167 & 27375 & 76820 & 8.4 & $3.2 \%$ & $10.5 \%$ & $298.6 \%$ & 27.4 \\
\hline 1996 & 216359 & 7893 & 23703 & 65338 & 8.3 & $3.4 \%$ & $10.6 \%$ & $300.3 \%$ & 27.4 \\
\hline 1997 & 195752 & 6871 & 20782 & 58309 & 8.5 & $3.4 \%$ & $10.3 \%$ & $302.5 \%$ & 28.5 \\
\hline 1998 & 178681 & 6152 & 17168 & 52809 & 8.6 & $4.1 \%$ & $9.3 \%$ & $279.1 \%$ & 29.0 \\
\hline 1999 & 202328 & 6643 & 19973 & 59023 & 8.9 & $4.7 \%$ & $9.6 \%$ & $300.7 \%$ & 30.5 \\
\hline 2000 & 209439 & 6747 & 20734 & 61073 & 9.1 & $4.7 \%$ & $9.6 \%$ & $307.3 \%$ & 31.0 \\
\hline 2001 & 179513 & 5473 & 16380 & 52454 & 9.6 & $5.0 \%$ & $8.9 \%$ & $299.3 \%$ & 32.8 \\
\hline 2002 & 170369 & 5017 & 16462 & 49152 & 9.8 & $5.4 \%$ & $9.4 \%$ & $328.1 \%$ & 34.0 \\
\hline 2003 & 180802 & 5119 & 17801 & 51264 & 10.0 & $5.3 \%$ & $9.6 \%$ & $347.7 \%$ & 35.3 \\
\hline 2004 & 193378 & 5320 & 19430 & 52772 & 9.9 & $4.7 \%$ & $9.8 \%$ & $365.2 \%$ & 36.3 \\
\hline 2005 & 187408 & 5169 & 19056 & 50192 & 9.7 & $4.4 \%$ & $9.9 \%$ & $368.6 \%$ & 36.3 \\
\hline 2006 & 173901 & 4847 & 16280 & 46318 & 9.6 & $4.1 \%$ & $9.1 \%$ & $335.9 \%$ & 35.9 \\
\hline 2007 & 169234 & 4806 & 16644 & 43783 & 9.1 & $3.9 \%$ & $9.6 \%$ & $346.3 \%$ & 35.2 \\
\hline 2008 & 196089 & 5108 & 15600 & 49126 & 9.6 & $4.0 \%$ & $7.8 \%$ & $305.4 \%$ & 38.4 \\
\hline
\end{tabular}

* En USD de 2012. **Por asalariado, en USD de 2012.

Fuente: Véase anexo 2. 
198 ECONOMÍA: TEORÍA Y PRÁCTICA • Nueva Época, número 45, julio-diciembre 2016

\section{Cuadro 1.2. Chile, 1964-2009}

\begin{tabular}{|c|c|c|c|c|c|c|c|c|c|}
\hline & 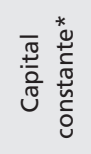 & 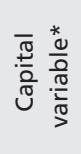 & 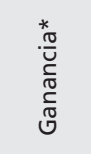 & 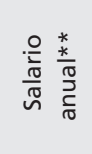 & 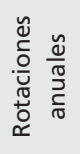 & 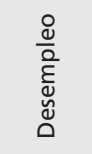 & 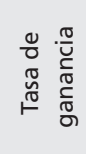 & 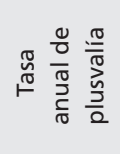 & 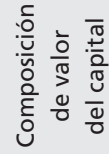 \\
\hline 1964 & 29518 & 2962 & 9053 & 7347 & 2.5 & & $27.9 \%$ & $305.6 \%$ & 10.0 \\
\hline 1965 & 30833 & 2795 & 8547 & 7827 & 2.8 & & $25.4 \%$ & $305.8 \%$ & 11.0 \\
\hline 1966 & 31466 & 2637 & 9228 & 8622 & 3.3 & & $27.1 \%$ & $350.0 \%$ & 11.9 \\
\hline 1967 & 29585 & 2675 & 8602 & 7971 & 3.0 & & $26.7 \%$ & $321.6 \%$ & 11.1 \\
\hline 1968 & 27981 & 2653 & 8223 & 8092 & 3.1 & & $26.8 \%$ & $309.9 \%$ & 10.5 \\
\hline 1969 & 27467 & 2769 & 8698 & 8224 & 3.0 & & $28.8 \%$ & $314.1 \%$ & 9.9 \\
\hline 1970 & 27223 & 2825 & 7832 & 8588 & 3.0 & $7.1 \%$ & $26.1 \%$ & $277.3 \%$ & 9.6 \\
\hline 1971 & 29952 & 3037 & 6900 & 11116 & 3.7 & $5.5 \%$ & $20.9 \%$ & $227.2 \%$ & 9.9 \\
\hline 1972 & 35890 & 3519 & 7358 & 12421 & 3.5 & $3.8 \%$ & $18.7 \%$ & $209.1 \%$ & 10.2 \\
\hline 1973 & 30398 & 2631 & 8034 & 7182 & 2.7 & $4.6 \%$ & $24.3 \%$ & $305.4 \%$ & 11.6 \\
\hline 1974 & 37399 & 2777 & 7487 & 7774 & 2.8 & $9.7 \%$ & $18.6 \%$ & $269.6 \%$ & 13.5 \\
\hline 1975 & 31298 & 2302 & 4242 & 5110 & 2.2 & $16.2 \%$ & $12.6 \%$ & $184.3 \%$ & 13.6 \\
\hline 1976 & 35295 & 2874 & 5719 & 6324 & 2.2 & $16.8 \%$ & $15.0 \%$ & $199.0 \%$ & 12.3 \\
\hline 1977 & 34294 & 3167 & 6344 & 7253 & 2.3 & $13.2 \%$ & $16.9 \%$ & $200.3 \%$ & 10.8 \\
\hline 1978 & 34177 & 3113 & 7005 & 7439 & 2.4 & $14.0 \%$ & $18.8 \%$ & $225.1 \%$ & 11.0 \\
\hline 1979 & 36458 & 3410 & 9510 & 8252 & 2.4 & $13.6 \%$ & $23.9 \%$ & $278.9 \%$ & 10.7 \\
\hline 1980 & 40968 & 4165 & 10992 & 10413 & 2.5 & $11.8 \%$ & $24.4 \%$ & $263.9 \%$ & 9.8 \\
\hline 1981 & 44628 & 5188 & 10848 & 11881 & 2.3 & $11.1 \%$ & $21.8 \%$ & $209.1 \%$ & 8.6 \\
\hline 1982 & 45636 & 4323 & 7402 & 9467 & 2.2 & $22.1 \%$ & $14.8 \%$ & $171.2 \%$ & 10.6 \\
\hline 1983 & 34646 & 3045 & 6240 & 6273 & 2.1 & $22.2 \%$ & $16.6 \%$ & $204.9 \%$ & 11.4 \\
\hline 1984 & 29349 & 2463 & 5657 & 5419 & 2.2 & $19.2 \%$ & $17.8 \%$ & $229.6 \%$ & 11.9 \\
\hline 1985 & 26035 & 1837 & 4319 & 4134 & 2.3 & $16.4 \%$ & $15.5 \%$ & $235.0 \%$ & 14.2 \\
\hline 1986 & 24264 & 1876 & 4869 & 4203 & 2.2 & $12.1 \%$ & $18.6 \%$ & $259.5 \%$ & 12.9 \\
\hline 1987 & 26890 & 1980 & 5952 & 4575 & 2.3 & $10.9 \%$ & $20.6 \%$ & $300.5 \%$ & 13.6 \\
\hline 1988 & 27968 & 2099 & 7114 & 4848 & 2.3 & $9.7 \%$ & $23.7 \%$ & $339.0 \%$ & 13.3 \\
\hline 1989 & 27674 & 2074 & 7325 & 5372 & 2.6 & $7.9 \%$ & $24.6 \%$ & $353.2 \%$ & 13.3 \\
\hline 1990 & 29088 & 2218 & 7109 & 5856 & 2.6 & $7.8 \%$ & $22.7 \%$ & $320.5 \%$ & 13.1 \\
\hline 1991 & 29871 & 2473 & 7770 & 6530 & 2.6 & $8.2 \%$ & $24.0 \%$ & $314.2 \%$ & 12.1 \\
\hline 1992 & 32244 & 2713 & 8412 & 7596 & 2.8 & $6.7 \%$ & $24.1 \%$ & $310.1 \%$ & 11.9 \\
\hline 1993 & 31924 & 2688 & 7719 & 7715 & 2.9 & $6.6 \%$ & $22.3 \%$ & $287.2 \%$ & 11.9 \\
\hline 1994 & 35795 & 3167 & 9067 & 8742 & 2.8 & $7.8 \%$ & $23.3 \%$ & $286.3 \%$ & 11.3 \\
\hline 1995 & 39951 & 3707 & 11489 & 10343 & 2.8 & $7.3 \%$ & $26.3 \%$ & $309.9 \%$ & 10.8 \\
\hline 1996 & 43848 & 4266 & 13565 & 11006 & 2.6 & $6.3 \%$ & $21.8 \%$ & $245.6 \%$ & 10.3 \\
\hline 1997 & 46123 & 4285 & 14175 & 11869 & 2.8 & $6.1 \%$ & $21.9 \%$ & $257.7 \%$ & 10.8 \\
\hline 1998 & 44809 & 4040 & 12371 & 11717 & 2.9 & $6.4 \%$ & $19.7 \%$ & $237.9 \%$ & 11.1 \\
\hline 1999 & 45397 & 3833 & 11262 & 11498 & 3.0 & $10.1 \%$ & $17.5 \%$ & $225.0 \%$ & 11.8 \\
\hline 2000 & 42967 & 3437 & 11350 & 10998 & 3.2 & $9.7 \%$ & $19.2 \%$ & $259.7 \%$ & 12.5 \\
\hline 2001 & 39763 & 2947 & 9607 & 9756 & 3.3 & $9.9 \%$ & $18.2 \%$ & $263.3 \%$ & 13.5 \\
\hline 2002 & 38591 & 2766 & 9101 & 9322 & 3.4 & $9.8 \%$ & $17.8 \%$ & $266.6 \%$ & 14.0 \\
\hline 2003 & 39695 & 2754 & 9617 & 9474 & 3.4 & $9.5 \%$ & $18.4 \%$ & $283.2 \%$ & 14.4 \\
\hline 2004 & 44819 & 3156 & 12441 & 10824 & 3.4 & $10.0 \%$ & $21.4 \%$ & $325.6 \%$ & 14.2 \\
\hline 2005 & 50497 & 3491 & 14999 & 12078 & 3.5 & $9.2 \%$ & $23.5 \%$ & $363.1 \%$ & 14.5 \\
\hline 2006 & 54670 & 3825 & 18342 & 12775 & 3.3 & $7.8 \%$ & $27.4 \%$ & $418.4 \%$ & 14.3 \\
\hline 2007 & 58399 & 3919 & 19223 & 13679 & 3.5 & $7.1 \%$ & $27.1 \%$ & $430.9 \%$ & 14.9 \\
\hline 2008 & 63164 & 3679 & 16129 & 14788 & 4.0 & $7.8 \%$ & $20.9 \%$ & $379.2 \%$ & 17.2 \\
\hline 2009 & 64586 & 4016 & 14806 & 14498 & 3.6 & $9.7 \%$ & $18.9 \%$ & $322.0 \%$ & 16.1 \\
\hline
\end{tabular}

* En USD de 2012. **Por asalariado, en USD de 2012.

Fuente: Véase anexo 2. 
Cuadro 1.3. Países Bajos, 1964-2009

\begin{tabular}{|c|c|c|c|c|c|c|c|c|c|}
\hline & 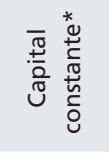 & 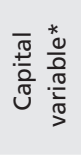 & 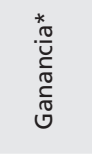 & 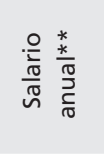 & 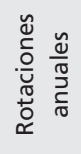 & 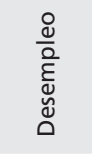 & 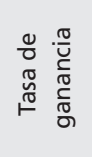 & 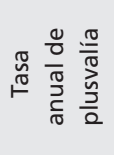 & 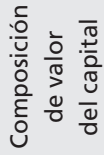 \\
\hline 1964 & & & & & 4.8 & & $14.0 \%$ & $265.4 \%$ & 18.0 \\
\hline 1965 & & & & & 5.1 & & $13.7 \%$ & $271.6 \%$ & 18.8 \\
\hline 1966 & & & & & 5.2 & & $12.4 \%$ & $247.2 \%$ & 19.0 \\
\hline 1967 & & & & & 5.5 & & $12.7 \%$ & $262.6 \%$ & 19.7 \\
\hline 1968 & & & & & 5.8 & & $12.6 \%$ & $280.1 \%$ & 21.2 \\
\hline 1969 & 107.080 & 4809 & 15826 & 31497 & 6.6 & & $14.1 \%$ & $329.1 \%$ & 22.3 \\
\hline 1970 & 117.024 & 4863 & 15564 & 33729 & 6.9 & $0.7 \%$ & $12.8 \%$ & $320.1 \%$ & 24.1 \\
\hline 1971 & 132.132 & 5364 & 16035 & 37337 & 7.0 & $0.9 \%$ & $11.7 \%$ & $298.9 \%$ & 24.6 \\
\hline 1972 & 150.010 & 6028 & 18499 & 43194 & 7.2 & $1.5 \%$ & $11.9 \%$ & $306.9 \%$ & 24.9 \\
\hline 1973 & 172.235 & 6473 & 21885 & 51600 & 8.0 & $1.6 \%$ & $12.2 \%$ & $338.1 \%$ & 26.6 \\
\hline 1974 & 176.451 & 6320 & 23598 & 52785 & 8.4 & $2.0 \%$ & $12.9 \%$ & $373.4 \%$ & 27.9 \\
\hline 1975 & 199.846 & 7631 & 21735 & 59716 & 7.8 & $2.8 \%$ & $10.5 \%$ & $284.8 \%$ & 26.2 \\
\hline 1976 & 188.426 & 6936 & 22686 & 56678 & 8.2 & $3.1 \%$ & $11.6 \%$ & $327.1 \%$ & 27.2 \\
\hline 1977 & 193.238 & 7247 & 21320 & 58467 & 8.1 & $3.1 \%$ & $10.6 \%$ & $294.2 \%$ & 26.7 \\
\hline 1978 & 214.663 & 8046 & 23359 & 64484 & 8.0 & $3.2 \%$ & $10.5 \%$ & $290.3 \%$ & 26.7 \\
\hline 1979 & 216.302 & 7638 & 22258 & 63815 & 8.4 & $3.3 \%$ & $9.9 \%$ & $291.4 \%$ & 28.3 \\
\hline 1980 & 210.015 & 7133 & 22310 & 60843 & 8.5 & $3.8 \%$ & $10.3 \%$ & $312.8 \%$ & 29.4 \\
\hline 1981 & 162.981 & 5457 & 18486 & 45489 & 8.3 & $6.0 \%$ & $11.0 \%$ & $338.7 \%$ & 29.9 \\
\hline 1982 & 139.361 & 4678 & 16053 & 39615 & 8.5 & $8.4 \%$ & $11.1 \%$ & $343.2 \%$ & 29.8 \\
\hline 1983 & 125.244 & 3995 & 15643 & 35734 & 8.9 & $10.2 \%$ & $12.1 \%$ & $391.5 \%$ & 31.3 \\
\hline 1984 & 107.305 & 3292 & 15548 & 30411 & 9.2 & $10.2 \%$ & $14.1 \%$ & $472.3 \%$ & 32.6 \\
\hline 1985 & 99.566 & 3067 & 14639 & 29044 & 9.5 & $9.1 \%$ & $14.3 \%$ & $477.2 \%$ & 32.5 \\
\hline 1986 & 127.844 & 4044 & 18137 & 38077 & 9.4 & $8.6 \%$ & $13.8 \%$ & $448.5 \%$ & 31.6 \\
\hline 1987 & 150.116 & 4692 & 19000 & 44302 & 9.4 & $8.5 \%$ & $12.3 \%$ & $404.9 \%$ & 32.0 \\
\hline 1988 & 151.038 & 4473 & 19480 & 43992 & 9.8 & $8.4 \%$ & $12.5 \%$ & $435.5 \%$ & 33.8 \\
\hline 1989 & 138.060 & 3780 & 19080 & 39623 & 10.5 & $7.6 \%$ & $13.5 \%$ & $504.7 \%$ & 36.5 \\
\hline 1990 & 157.002 & 4424 & 21287 & 45584 & 10.3 & $6.9 \%$ & $13.2 \%$ & $481.2 \%$ & 35.5 \\
\hline 1991 & 151.636 & 4401 & 20291 & 44536 & 10.1 & $6.5 \%$ & $13.0 \%$ & $461.1 \%$ & 34.5 \\
\hline 1992 & 162.439 & 4803 & 20595 & 47877 & 10.0 & $6.5 \%$ & $12.3 \%$ & $428.7 \%$ & 33.8 \\
\hline 1993 & 150.487 & 4586 & 18114 & 43828 & 9.6 & $7.5 \%$ & $11.7 \%$ & $395.0 \%$ & 32.8 \\
\hline 1994 & 153.445 & 4414 & 20380 & 44427 & 10.1 & $8.5 \%$ & $12.9 \%$ & $461.7 \%$ & 34.8 \\
\hline 1995 & 170.631 & 4787 & 22919 & 48818 & 10.2 & $8.1 \%$ & $13.1 \%$ & $478.8 \%$ & 35.6 \\
\hline 1996 & 165.961 & 4474 & 22532 & 47107 & 10.5 & $7.5 \%$ & $13.2 \%$ & $503.6 \%$ & 37.1 \\
\hline 1997 & 145.856 & 3815 & 20782 & 41581 & 10.9 & $6.6 \%$ & $13.9 \%$ & $544.7 \%$ & 38.2 \\
\hline 1998 & 145.624 & 3801 & 20098 & 42135 & 11.1 & $5.1 \%$ & $13.5 \%$ & $528.7 \%$ & 38.3 \\
\hline 1999 & 142.650 & 3655 & 18826 & 41058 & 11.2 & $4.3 \%$ & $12.9 \%$ & $515.1 \%$ & 39.0 \\
\hline 2000 & 126.460 & 3052 & 17174 & 36421 & 11.9 & $3.8 \%$ & $13.3 \%$ & $562.8 \%$ & 41.4 \\
\hline 2001 & 125.895 & 3026 & 16604 & 36188 & 12.0 & $3.5 \%$ & $12.9 \%$ & $548.8 \%$ & 41.6 \\
\hline 2002 & 141.828 & 3417 & 17451 & 39234 & 11.5 & $4.1 \%$ & $12.0 \%$ & $510.7 \%$ & 41.5 \\
\hline 2003 & 173.377 & 4091 & 20773 & 47538 & 11.6 & $5.4 \%$ & $11.7 \%$ & $507.8 \%$ & 42.4 \\
\hline 2004 & 187.609 & 4354 & 23351 & 52520 & 12.1 & $6.5 \%$ & $12.2 \%$ & $536.3 \%$ & 43.1 \\
\hline 2005 & 187.399 & 4240 & 25138 & 51467 & 12.1 & $6.5 \%$ & $13.1 \%$ & $592.9 \%$ & 44.2 \\
\hline 2006 & 184.194 & 4100 & 25931 & 51455 & 12.5 & $5.5 \%$ & $13.8 \%$ & $632.4 \%$ & 44.9 \\
\hline 2007 & 201.186 & 4411 & 28719 & 56210 & 12.7 & $4.5 \%$ & $14.0 \%$ & $651.1 \%$ & 45.6 \\
\hline 2008 & 221.883 & 4882 & 30386 & 60976 & 12.5 & $3.8 \%$ & $13.4 \%$ & $622.5 \%$ & 45.5 \\
\hline 2009 & 212.857 & 4764 & 24425 & 58552 & 12.3 & $4.8 \%$ & $11.2 \%$ & $512.7 \%$ & 44.7 \\
\hline
\end{tabular}

* En USD de 2012. **Por asalariado, en USD de 2012.

Fuente: Véase anexo 2. 
200 ECONOMÍA: TEORÍA Y PRÁCTICA • Nueva Época, número 45, julio-diciembre 2016

Cuadro 1.4. EU, 1960-2009

\begin{tabular}{|c|c|c|c|c|c|c|c|c|c|}
\hline & $\begin{array}{ll}\overline{0} & \stackrel{0}{ \pm} \\
\frac{ \pm}{0} & \frac{\pi}{0} \\
\frac{\pi}{0} & \frac{1}{0} \\
0 & 0\end{array}$ & 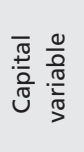 & $\begin{array}{l}\frac{\pi}{U} \\
\frac{\pi}{\pi} \\
\frac{\pi}{0} \\
0\end{array}$ & $\begin{array}{ll}\frac{0}{\frac{1}{T}} & \frac{*}{\pi} \\
\frac{\pi}{\sqrt{N}} & \frac{c}{2} \\
\frac{2}{\pi}\end{array}$ & 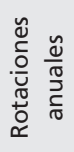 & 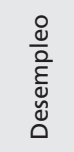 & 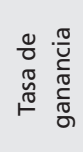 & 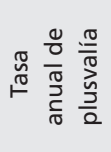 & 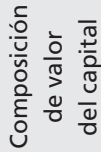 \\
\hline 1960 & 113343 & 5871 & 14943 & 33885 & 5.8 & $5.5 \%$ & $12.5 \%$ & $254.5 \%$ & 19.3 \\
\hline 1961 & 116431 & 5855 & 15517 & 34642 & 5.9 & $6.7 \%$ & $12.7 \%$ & $265.0 \%$ & 19.9 \\
\hline 1962 & 117249 & 5770 & 16312 & 35725 & 6.2 & $5.5 \%$ & $13.3 \%$ & $282.7 \%$ & 20.3 \\
\hline 1963 & 118803 & 5870 & 16854 & 36649 & 6.2 & $5.7 \%$ & $13.5 \%$ & $287.1 \%$ & 20.2 \\
\hline 1964 & 120051 & 5915 & 17416 & 37710 & 6.4 & $5.2 \%$ & $13.8 \%$ & $294.4 \%$ & 20.3 \\
\hline 1965 & 120540 & 5632 & 18203 & 38334 & 6.8 & $4.5 \%$ & $14.4 \%$ & $323.2 \%$ & 21.4 \\
\hline 1966 & 120921 & 5580 & 18053 & 39323 & 7.0 & $3.8 \%$ & $14.3 \%$ & $323.6 \%$ & 21.7 \\
\hline 1967 & 124242 & 5956 & 17346 & 40043 & 6.7 & $3.8 \%$ & $13.3 \%$ & $291.2 \%$ & 20.9 \\
\hline 1968 & 126255 & 5960 & 17159 & 41154 & 6.9 & $3.6 \%$ & $13.0 \%$ & $287.9 \%$ & 21.2 \\
\hline 1969 & 127516 & 5776 & 16301 & 41754 & 7.2 & $3.5 \%$ & $12.2 \%$ & $282.2 \%$ & 22.1 \\
\hline 1970 & 133465 & 5885 & 15040 & 42329 & 7.2 & $4.9 \%$ & $10.8 \%$ & $255.6 \%$ & 22.7 \\
\hline 1971 & 138075 & 5841 & 15820 & 42843 & 7.3 & $5.9 \%$ & $11.0 \%$ & $270.9 \%$ & 23.6 \\
\hline 1972 & 138879 & 5751 & 16557 & 43609 & 7.6 & $5.6 \%$ & $11.4 \%$ & $287.9 \%$ & 24.1 \\
\hline 1973 & 141869 & 5636 & 16958 & 44346 & 7.9 & $4.9 \%$ & $11.5 \%$ & $300.9 \%$ & 25.2 \\
\hline 1974 & 155666 & 5797 & 15458 & 43815 & 7.6 & $5.6 \%$ & $9.6 \%$ & $266.6 \%$ & 26.9 \\
\hline 1975 & 158172 & 6495 & 16140 & 43647 & 6.7 & $8.5 \%$ & $9.8 \%$ & $248.5 \%$ & 24.4 \\
\hline 1976 & 156199 & 6516 & 16498 & 44554 & 6.8 & $7.7 \%$ & $10.1 \%$ & $253.2 \%$ & 24.0 \\
\hline 1977 & 153608 & 6262 & 16843 & 44784 & 7.2 & $7.1 \%$ & $10.5 \%$ & $268.9 \%$ & 24.5 \\
\hline 1978 & 152169 & 6036 & 17118 & 44933 & 7.4 & $6.1 \%$ & $10.8 \%$ & $283.6 \%$ & 25.2 \\
\hline 1979 & 156043 & 5971 & 16464 & 45149 & 7.6 & $5.8 \%$ & $10.2 \%$ & $275.7 \%$ & 26.1 \\
\hline 1980 & 165156 & 6389 & 15573 & 45772 & 7.2 & $7.1 \%$ & $9.1 \%$ & $243.8 \%$ & 25.9 \\
\hline 1981 & 166555 & 6373 & 16328 & 45511 & 7.1 & $7.6 \%$ & $9.4 \%$ & $256.2 \%$ & 26.1 \\
\hline 1982 & 171719 & 7156 & 16195 & 46460 & 6.5 & $9.7 \%$ & $9.1 \%$ & $226.3 \%$ & 24.0 \\
\hline 1983 & 167077 & 6722 & 17368 & 46762 & 7.0 & $9.6 \%$ & $10.0 \%$ & $258.4 \%$ & 24.9 \\
\hline 1984 & 161176 & 6183 & 19213 & 47382 & 7.7 & $7.5 \%$ & $11.5 \%$ & $310.7 \%$ & 26.1 \\
\hline 1985 & 160920 & 6576 & 19366 & 48106 & 7.3 & $7.2 \%$ & $11.6 \%$ & $294.5 \%$ & 24.5 \\
\hline 1986 & 162849 & 6567 & 19118 & 49131 & 7.5 & $7.0 \%$ & $11.3 \%$ & $291.1 \%$ & 24.8 \\
\hline 1987 & 161958 & 6086 & 19590 & 49734 & 8.2 & $6.2 \%$ & $11.7 \%$ & $321.9 \%$ & 26.6 \\
\hline 1988 & 160828 & 5710 & 20481 & 50477 & 8.8 & $5.5 \%$ & $12.3 \%$ & $358.7 \%$ & 28.2 \\
\hline 1989 & 160630 & 5756 & 20484 & 50503 & 8.8 & $5.3 \%$ & $12.3 \%$ & $355.9 \%$ & 27.9 \\
\hline 1990 & 161442 & 6020 & 19956 & 51151 & 8.5 & $5.6 \%$ & $11.9 \%$ & $331.5 \%$ & 26.8 \\
\hline 1991 & 162673 & 6221 & 19907 & 52001 & 8.4 & $6.8 \%$ & $11.8 \%$ & $320.0 \%$ & 26.1 \\
\hline 1992 & 163927 & 6236 & 20613 & 53500 & 8.6 & $7.5 \%$ & $12.1 \%$ & $330.5 \%$ & 26.3 \\
\hline 1993 & 163984 & 5891 & 20969 & 53603 & 9.1 & $6.9 \%$ & $12.3 \%$ & $356.0 \%$ & 27.8 \\
\hline 1994 & 163837 & 5686 & 21949 & 53507 & 9.4 & $6.1 \%$ & $12.9 \%$ & $386.0 \%$ & 28.8 \\
\hline 1995 & 165016 & 5701 & 22624 & 53666 & 9.4 & $5.6 \%$ & $13.3 \%$ & $396.8 \%$ & 28.9 \\
\hline 1996 & 165754 & 5638 & 24046 & 53953 & 9.6 & $5.4 \%$ & $14.0 \%$ & $426.5 \%$ & 29.4 \\
\hline 1997 & 167442 & 5680 & 25121 & 54956 & 9.7 & $4.9 \%$ & $14.5 \%$ & $442.3 \%$ & 29.5 \\
\hline 1998 & 169652 & 5841 & 25275 & 57051 & 9.8 & $4.5 \%$ & $14.4 \%$ & $432.7 \%$ & 29.0 \\
\hline 1999 & 172885 & 5780 & 25642 & 58660 & 10.1 & $4.2 \%$ & $14.4 \%$ & $443.6 \%$ & 29.9 \\
\hline 2000 & 175979 & 5565 & 25673 & 60835 & 10.9 & $4.0 \%$ & $14.1 \%$ & $461.4 \%$ & 31.6 \\
\hline 2001 & 181225 & 5919 & 25611 & 61808 & 10.4 & $4.7 \%$ & $13.7 \%$ & $432.7 \%$ & 30.6 \\
\hline 2002 & 186905 & 5990 & 26020 & 63114 & 10.5 & $5.8 \%$ & $13.5 \%$ & $434.4 \%$ & 31.2 \\
\hline 2003 & 189754 & 5759 & 26652 & 64852 & 11.3 & $6.0 \%$ & $13.6 \%$ & $462.8 \%$ & 32.9 \\
\hline 2004 & 198263 & 5601 & 28515 & 65283 & 11.7 & $5.5 \%$ & $14.0 \%$ & $509.1 \%$ & 35.4 \\
\hline 2005 & 205564 & 5536 & 29941 & 65429 & 11.8 & $5.1 \%$ & $14.2 \%$ & $540.9 \%$ & 37.1 \\
\hline 2006 & 212762 & 5642 & 31202 & 65965 & 11.7 & $4.6 \%$ & $14.3 \%$ & $553.0 \%$ & 37.7 \\
\hline 2007 & 216126 & 5818 & 29220 & 66838 & 11.5 & $4.6 \%$ & $13.2 \%$ & $502.2 \%$ & 37.1 \\
\hline 2008 & 235865 & 5941 & 28313 & 67774 & 11.4 & $5.8 \%$ & $11.7 \%$ & $476.6 \%$ & 39.7 \\
\hline 2009 & 241358 & 6883 & 28299 & 68649 & 10.0 & $9.3 \%$ & $11.4 \%$ & $411.2 \%$ & 35.1 \\
\hline
\end{tabular}

* En USD de 2012. **Por asalariado, en USD de 2012.

Fuente: Véase anexo 2. 


\section{Anexo 2}

\section{Chile}

Capital constante fijo: Serie oficial del Banco Central de Chile (2011b), para el periodo 1985-2009. Para el periodo previo, se utilizaron las series de stock de capital fijo neto de Souza y Feu (2005) y los índices de precios implícitos de la formación bruta de capital fijo de Braun et al. (2000). Para el cálculo del stock de capital en construcción no residencial (que Souza y Feu no discriminan en su serie), se utilizó la serie de inversión de Aguilar y Collinao (2001). Finalmente, para 1964-1984, se aplicaron las tasas de variación de esta serie a la del Banco Central. Capital constante circulante: Series de Consumo Intermedio del Banco Central de Chile (2001; 2006; 2011a), desde 1986. Para los años previos, datos de Marcel (1986, p. 103); para 1975-1984, extrapolados hacia atrás y hacia adelante con base en la relación del consumo intermedio con el PBI.

Capital variable: Serie de Remuneraciones de la CEPAL 1964-2009 (Comisión Económica para América Latina y el Caribe, s.f.).

Stock de inventarios: Estimado a partir de la serie de Haindl y Fuentes (1986) para 1960-1984 y estadísticas oficiales de variación de existencias del Banco Central de Chile (2001; 2006; 2011a).

Ganancias: Serie de Excedente Neto de Explotación de la CEPAL 1964-2009 (Comisión Económica para América Latina y el Caribe, s.f.).

Asalariados: Serie del Banco Central de Chile (2001) y el Instituto Nacional de Estadística (s.f.).

\section{Japón}

Capital constante fijo: Series de stock de capital reproductivo en Construcción no-residencial, Maquinaria y Equipo de Transporte ("Net Fixed Assets", excluyendo "Residential Buildings", de "Closing Stocks, Capital Transactions and Reconciliations of Assets and Liabilities for the Nation"), del Statistics Bureau of Japan (s.f.a; s.f.b).

Capital constante circulante: Serie de consumo intermedio ("Intermediate Inputs", de "Gross Domestic Product and Factor Income Classified"), del Statistics Bureau of Japan (s.f.a; s.f.b).

Capital variable: Serie de remuneraciones ("Compensation of Employees", de "Gross Domestic Product and Factor Income Classified"), del Statistics Bureau of Japan (s.f.a; s.f.b). 
Stock de inventarios: Serie de stocks de inventarios (“Stocks", de "Closing Stocks, Capital Transactions and Reconciliations of Assets and Liabilities for the Nation"), del Statistics Bureau of Japan (s.f.a; s.f.b).

Ganancias: Serie de excedente neto de explotación ("Operating Surplus", de "Gross Domestic Product and Factor Income Classified"), del Statistics Bureau of Japan (s.f.a; s.f.b).

Asalariados: Serie de asalariados y desempleados ("Employee" de "Employed Person by Status in Employment”), del Statistics Bureau of Japan (s.f.a; s.f.b).

\section{Países Bajos}

Capital constante fijo: Estimación propia mediante el método de inventarios permanentes a partir de las series de inversión de Groote, Albersy Jong (1996) y de la Organización para la Cooperación y el Desarrollo Económicos (s.f.) (“Other Buldings" y "Machinery and Equipment") y las series de precios del Central Bureau voor de Statistiek (s.f.a; s.f.b).

Capital constante circulante: Series de precios del Central Bureau voor de Statistiek (s.f.a; s.f.b).

Capital variable: Serie de remuneraciones ("Compensation of employees" de “Approaches of Domestic Product 1969-2012”), del Central Bureau voor de Statistiek (s.f.a; s.f.b).

Stock de inventarios: Estimado a partir de los cálculos de Taminiau-van Veen, Schaa y Bergen (2009), para 2004, y de variación de existencias ("Changes in Inventories" de "Approaches of Domestic Product 1969-2012"), del Central Bureau voor de Statistiek (s.f.a; s.f.b).

Ganancias: Serie de excedente neto de explotación ("Net Operating Surplus" de “Approaches of Domestic Product 1969-2012”), del Central Bureau voor de Statistiek (s.f.a; s.f.b).

Asalariados: Serie de asalariados y desempleados ("Employees" de "Labour Accounts 1969-2012”), del Bureau voor de Statistiek (s.f.a; s.f.b), sólo desde 1969.

\section{Estados Unidos}

Capital constante fijo: Series de stock de capital reproductivo en Construcción no-residencial, Maquinaria y Equipo de Transporte ("Fixed Assets - Equipment \& Structures in Residential, Private \& Government", tablas 2.1 y 7.1), del Bureau of Economic Analysis (s.f.a; s.f.b).

Capital constante circulante: Serie de consumo intermedio de EUKLEMS (s.f.) 1977-2009, extrapolada hacia atrás con base en la relación con el PIB. 
Capital variable: Serie de remuneraciones ("Compensation of Employees", tabla 1.12 "National Income by Type of Income"), del Bureau of Economic Analysis (s.f.a; s.f.b).

Stock de inventarios: Serie de stock de inventarios ("Private Inventories", tabla 5.8.5 "Save and Investment"), del Bureau of Economic Analysis (s.f.a; s.f.b).

Ganancias: Serie de excedente neto de explotación ("National Income", menos "Compensation of Employees", menos "Taxes on Production and Imports", más "Subsidies", tabla 1.12 "National Income by Type of Income"), del Bureau of Economic Analysis (s.f.a; s.f.b).

Asalariados: Serie de asalariados (“All Employees, Non-farm”), del Bureau of Labor Statistics (s.f.a; s.f.b).

Los datos se convirtieron a dólares corrientes utilizando los tipos de cambio nominales anuales oficiales para luego deflactarlos por el índice de precios implícitos del producto estadounidense.

\section{REFERENCIAS BIBLIOGRÁFICAS}

Aguilar, Ximena, y Collinao, María Paz (2001), "Cálculo del stock de capital para Chile 1985-2000", documento de trabajo 133, Banco Central de Chile.

Alemi, Piruz, y Foley, Duncan (1997), "The Circuit of capital, us manufacturing and non-financial corporate business sectors 1947-1993", mimeo.

Banco Central de Chile (2001), Indicadores económicos y sociales de Chile 1960-2000, Banco Central de Chile, Santiago.

(2006), “Cuentas Nacionales de Chile 1996-2005". Consultado el 1 de septiembre de 2013, en: http://si3.bcentral.cl/estadisticas/Principal1/informes/CCNN/ ANUALES/anuarioCCNN_1996_2005.html.

(2011a), "Cuentas Nacionales de Chile 2003-2010". Consultado el 1 de septiembre de 2013, en: http://si3.bcentral.cl/estadisticas/Principal1/informes/CCNN /ANUALES/anuarioCCNN_2003_2010.html.

(2011b) "Stock de capital en Chile (1985-2005): Metodología y resultados. Estudios Económicos Estadísticos 63 - abril 2008. Series de stock de capital y consumo de capital fijo. Periodo 1985-2009, referencia 2003". Consultado el 1 de septiembre de 2013, en: http://si3.bcentral.cl/estadisticas/Principal1/Estudios/CCNN/ sector_institucional/SEE63_seriesstockcapitalconsumocapitalfijo_2011.xls.

Braun, Juan; Braun, Matías; Briones, Ignacio; Díaz, José; Lüders, Rolf, y Wagner, Gert 
(2000), "Economía chilena 1810-1995: estadísticas históricas", documento de trabajo 187, Instituto de Economía de la Universidad Católica de Chile.

Bureau of Economic Analysis (s.f.a), "Fixed Assets Account Tables". Consultado el 24 de julio de 2013, en: http:/www.bea.gov/iTable/iTable.cfm?ReqID=10\&step=1 \#reqid=10\&step=1\&isuri=1.

(s.f.b), "National Data Tables". Consultado el 24 de julio de 2013, en: http:// www.bea.gov/iTable/iTable.cfm?ReqID=9\&step=1\#reqid=9\&step=1\&isuri=1.

Bureau of Labor Statistics (s.f.), "Bureau of Labor Statistics". Consultado el 24 de julio de 2013, en: http://data.bls.gov/pdq/SurveyOutputServlet.

Central Bureau voor de Statistiek (s.f.a), "National Accounts; Approaches of Domestic Product (GDP); 1969-2012”. Consultado el 27 de julio de 2013, en http://statline.cbs.nl/Statweb/selection/?DM=SLEN\&PA=81117ENG\&LA=EN\&VW=T. (s.f.b), "Labour Accounts; Employment, Economic Activity, Sex; 1969-2012”. Consultado el 27 de julio de 2013, en: http://statline.cbs.nl/Statweb/selection/? $\mathrm{DM}=\mathrm{SLEN} \& \mathrm{PA}=81108 \mathrm{ENG} \& \mathrm{LA}=\mathrm{EN} \& \mathrm{VW}=\mathrm{T}$.

Comisión Económica para América Latina y el Caribe (s.f.), "Relaciones entre los principales agregados de cuentas nacionales a precios corrientes en moneda nacional", en CEPALSTAT, base de datos de la CEPAL. Consultado el 1 de septiembre de 2013, en: http://estadisticas.cepal.org/cepalstat/web_cepalstat/estadisticasindicadores. asp.

Duménil, Gerard, y Levy, Dominique (2002), “The Profit Rate. Where and How Much Did It Fall. USA 1948-2000”. Consultado el 24 de julio de 2013, en: http://www. jourdan.ens.fr/levy/.

(2005) "From Prosperity to Neoliberalism. Europe Before and After the Structural Crisis of the 1970's". Consultado el 24 de julio de 2013, en: http://www. jourdan.ens.fr/levy/.

EUKLEMS (s.f.), "United States-NAICs Based (Revised)". Consultado el 24 de julio de 2013, en: http://euklems.net/data/09I/usa-naics_output_09Irev.xls.

Fichtenbaum, Rudy (1988), "Business Cycles, Turnover and the Rate of Profit: an Empirical Test of Marxian Crisis Theory”, Eastern Economic Journal, 13 (3), pp. 21-28.

Groote, Peter; Albers, Ronald, y Jong, Herman de (1996), “A Standardized Time Series of the Stock of Fixed Capital in the Netherlands, 1900-1995", Groningen Growth \& Development Center Working Paper 25, Universidad de Groningen.

Guerriero, Marta (2012), "The Labour Share of Income Around the World. Evidence from a Panel Dataset", Development Economics and Public Policy Working Papers 32/2012, University of Manchester. 
Haindl, Erik, y Fuentes, Rodrigo (1986), "Estimación del stock de capital en Chile 19601984”, Estudios de Economía, 13 (1), pp. 39-72.

Iñigo, Juan (2007), La formación económica de la sociedad Argentina, Buenos Aires, Imago Mundi.

Instituto Nacional de Estadística (s.f.), "Ocupados por categoría, total país". Consultado el 1 de septiembre de 2013, en: http:/www.ine.cl/canales/chile_estadistico/ mercado_del_trabajo/empleo/empalmadas/c98/cambossexos.xls.

Jones, Peter (2012), "Depreciation, devaluation and the rate of profit", mimeo.

Lindenboim, Javier; Kennedy, Damián, y Graña, Juan (2011), "Distribución funcional y demanda agregada en Argentina. Sesenta años en perspectiva internacional", documento de trabajo 16 CPED-UBA, Universidad de Buenos Aires.

Maddison-Project (2013), "Maddison-Project 2013 version". Consultado el 12 de julio de 2013, en: http://www.ggdc.net/maddison/maddison-project/home.htm.

Maito, Esteban Ezequiel (2012), "La tasa de ganancia en Chile 1986-2009”, Razón y Revolución, 0 (24), pp. 43-63.

(2014), "La transitoriedad histórica del capital. La tendencia descendente de la tasa de ganancia desde el siglo XIX", Razón y Revolución, 0 (26), pp. 129-159. (2015), "Cien años de acumulación de capital en Argentina: tasa de ganancia, composición de valor del capital y distribución funcional del producto", Ensayos de Economía, 0 (47), pp. 37-62.

Marcel, Mario (1986), "Diez años del IvA en Chile", Colección Estudios CIEPLAN, 0 (19), pp. 83-134.

Mariña, Abelardo, y Moseley, Fred (2001), "La tasa general de ganancia y sus determinantes en México, 1950-1999”, Economía, Teoría y Práctica, 0 (15), pp. 35-65.

Marquetti, Adalmir; Maldonado, Eduardo, y Lautert, Vladimir (2014), "La tasa de ganancia en Brasil, 1953-2003”, Razón y Revolución, 0 (27), pp. 89-114.

Marx, Karl (1968a), El capital, t. I, México, Fondo de Cultura Económica. (1968b), El capital, t. II, México, Fondo de Cultura Económica.

(2007), Elementos fundamentales para la crítica de la economía política (Grundrisse), t. III, México, Siglo XXI.

(2012), El capital, t. III, México, Fondo de Cultura Económica.

Martínez, Gloria, y Valle, Alejandro (2011), "Differences in Surplus-value Rates Between Developed and Under-developed Countries: An Analysis Based on Differences in Productivity and Capital Composition", Marxism 21, 8 (1), pp. 175-204.

Organización para la Cooperación y el Desarrollo Económicos (s.f.), “OECD.Stat”. Consultado el 27 de julio de 2013, en: http://stats.oecd.org/Index.aspx?DatasetCode =SNA_TABLE1\#. 
Reati, Angelo (1986), "The Rate of Profit and the Organic Composition of Capital in the Post 1945 Long Wave. The Case of British Manufacturing Industry from 1959 to 1981", Fernand Braudel Center Review, 9 (4), pp. 515-571.

Reati, Angelo, y Roberts, Charles (1989), “The Rate of Profit and the Organic Composition of Capital in the Post 1945 Long Wave. The Case of French Manufacturing Industry from 1959 to 1981", International Journal of Political Economy, 19 (1), pp. 10-32.

Reuten, Geert (2005), “On the Quantitative Homology Between Circulating Capital and Capital Value", ponencia al XV International Symposium of Marxian Theory, del 11 al 14 de julio de 2005, Universidad Autónoma Metropolitana, México. [en línea] Consultado el 1 de mayo de 2016, en: http://www.azc.uam.mx/ socialesyhumanidades/06/departamentos/economia/PDF/10\%20Geert\%20 Reuten.pdf.

Souza, Marcos, y Feu, Aumara (2005), “Capital stock in Latin America: 1950-2000”, Economy \& Energy, 0 (50), pp. 2-20.

Statistics Bureau of Japan (s.f.a), "Historical Statistics of Japan". Consultado el 8 de agosto de 2013, en: http://www.stat.go.jp/english/data/chouki/03.htm.

_ (s.f.b), “Japan Statistical Yearbook". Consultado el 8 de agosto de 2013, en: http://www.stat.go.jp/english/data/nenkan/index.htm.

Taminiau-van Veen, Puck, Schaaf, Sandra, y Bergen, Dirk van den (2009), "Measuring Inventories in the Dutch National Accounts", CBS Discussion Paper 09019, Netherlands. 